\title{
Genome-Wide Identification of MAPKK and MAPKKK Gene Families in Tomato and Transcriptional Profiling Analysis during Development and Stress Response
}

\author{
Jian Wu', Jie Wang', Changtian Pan, Xiaoyan Guan, Yan Wang, Songyu Liu, Yanjun He, Jingli Chen, \\ Lifei Chen, Gang Lu*
}

Key Laboratory of Horticultural Plant Growth, Development and Biotechnology, Agricultural Ministry of China, Department of Horticulture, Zhejiang University, Hangzhou, People's Republic of China

\begin{abstract}
Mitogen-activated protein kinase (MAPK) cascades have important functions in plant growth, development, and response to various stresses. The MAPKK and MAPKKK gene families in tomato have never been systematically analyzed. In this study, we performed a genome-wide analysis of the MAPKK and MAPKKK gene families in tomato and identified 5 MAPKK genes and 89 MAPKKK genes. Phylogenetic analyses of the MAPKK and MAPKKK gene families showed that all the MAPKK genes formed four groups (groups A, B, C, and D), whereas all the MAPKKK genes were classified into three subfamilies, namely, MEKK, RAF, and ZIK. Evolutionary analysis showed that whole genome or chromosomal segment duplications were the main factors responsible for the expansion of the MAPKK and MAPKKK gene families in tomato. Quantitative real-time RT-PCR analysis showed that the majority of MAPKK and MAPKKK genes were expressed in all tested organs with considerable differences in transcript levels indicating that they might be constitutively expressed. However, the expression level of most of these genes changed significantly under heat, cold, drought, salt, and Pseudomonas syringae treatment. Furthermore, their expression levels exhibited significant changes in response to salicylic acid and indole-3-acetic acid treatment, implying that these genes might have important roles in the plant hormone network. Our comparative analysis of the MAPKK and MAPKKK families would improve our understanding of the evolution and functional characterization of MAPK cascades in tomato.
\end{abstract}

Citation: Wu J, Wang J, Pan C, Guan X, Wang Y, et al. (2014) Genome-Wide Identification of MAPKK and MAPKKK Gene Families in Tomato and Transcriptional Profiling Analysis during Development and Stress Response. PLoS ONE 9(7): e103032. doi:10.1371/journal.pone.0103032

Editor: Dawn Sywassink Luthe, Pennsylvania State University, United States of America

Received February 13, 2014; Accepted June 25, 2014; Published July 18, 2014

Copyright: $(2014$ Wu et al. This is an open-access article distributed under the terms of the Creative Commons Attribution License, which permits unrestricted use, distribution, and reproduction in any medium, provided the original author and source are credited.

Funding: This work was supported by the Grants from the Nation Natural Science Foundation of China [Grant numbers 31071337, 31271633] and the Natural Science Foundation of Zhejiang province, China (R3110209). The funders had no role in study design, data collection and analysis, decision to publish, or preparation of the manuscript.

Competing Interests: The authors have declared that no competing interests exist.

*Email: glu@zju.edu.cn

9 These authors contributed equally to this work.

\section{Introduction}

Mitogen-activated protein kinase (MAPK) cascades, which are widely distributed in eukaryotes, have an important function in the diverse developmental and physiological processes of plants, and in response to various biotic and abiotic stresses [1,2]. Each MAPK cascade consists of three protein kinases: MAPKs, MAPK kinases (MAPKKs/MKKs), and MAPKK kinases (MAPKKKs/ MEKKs). MAPKKK activates MAPKK through the phosphorylation of serine and serine/threonine residues in its T-loop. Similarly, MAPKK activates MAPK through the phosphorylation of tyrosine and threonine residues in the TEY or TDY motif between kinase subdomains VII and VIII. Plant MAPK cascade genes were first reported in Arabidopsis. Up to now, MAPK cascade family genes have been identified in many other plant species, including poplar, rice, soybean, maize, tomato and $N$. benthamiana [3-12].

In plants, the number of MAPKK family genes varies markedly across species. The estimated number is 10 in Arabidopsis, eight in rice, 11 in soybean, 11 in poplar and 12 in Brachypodium distachyon. According to phylogenetic analyses, all MAPKKs can be classified into four groups (groups A-D). The function of the group A MAPKK members, including AtMAPKK1, AtMAPKK2, and AtMAPKK6, in Arabidopsis has been detailed studied. AtMAPKK2 is shown to play an important role not only mediates innate immunity responses but also has an important function in the cold and salt signaling transduction pathway $[13,14]$. AtMAPKK1 also has essential functions in pathogen defence and have functional redundancy with AtMAPKK2 [13,15]. AtMAPKK6 acts in upstream of AtMAPK13 in yeast cells [16]. Functional data on MAPKK family members belonging to the other three subgroups are limited. Only one AtMAPKK3 belonging to group $\mathrm{B}$ was proved to function in pathogen resistance and participate in jasmonate signal transduction pathway in Arabidopsis [17,18].

MAPKKK is a large gene family containing 80, 75, 74 and 150 members in Arabidopsis, rice, maize and soybean, respectively [7,19-21]. All MAPKKK genes have been divided into three major groups, namely, RAF, MEKK, and ZIK. The RAF subfamily in rice, maize, and Arabidopsis has 48, 43, and 46 
members, respectively [20-22]. This subfamily contains a conserved catalytic and RAF-specific signature GTXX (W/Y) MAPE [22]. Plant MEKK-like MAPKKK genes also harbor a conserved catalytic domain and conserved signature G (T/S) PX (F/Y/W) MAPEV, similar to animal MEKKs. The ZIK subfamily contains a conserved signature GTPEFMAPE (L/V/M) (Y/F/L) across these members. Functional data on MEKK-like genes are more readily available than that on the other two subfamilies. In Arabidopsis, three MAPKKK genes named ANP1, ANP2, and $A N P 3$ have an important function in the signal transduction pathways that control plant cell division [23,24]. Another Arabidopsis MEKK-like gene (MEKKl) is involved in stress response and participates in signal transduction in diverse development process $[25,26]$. A MAPKKK gene, $Y O D A$ regulates stomatal development in Arabidopsis [27]. The functional characteristics of MEKK-like genes from other species, such as tobacco and Solanum chacoense have been studied in depth $[28,29]$. In tomato, SIMAPKKK $\alpha$ positively regulates cell death associated with both plant immunity and disease resistance [30]. SlMAPKKKE is involved in signaling networks associated with plant immunity [31]. The functions of some RAF subfamily members have also been investigated in Arabidopsis and other plant species [3]. CTR1 and EDR1, belonging to the Arabidopsis RAF MAPKKK subfamily, negatively regulates ethylene signaling transduction and participates in pathogen resistance [32,33]. $M A P 3 K \delta 4$, an Arabidopsis Raf-like MAP3K, has a function in the regulation of plant growth and shoot branching [34]. A rice RAFlike MAPKKK named ILAl regulates mechanical tissue formation [35]. DSM1 is involved in rice drought resistance [36]. Function analysis of ZIK-like genes is limited. However, most rice ZIK-like MAPKKK genes can be upregulated by at least one abiotic stress [20], indicating that they might be involved in stress signaling transduction pathways.

Up to now, only four MAPKK genes (SlMAPKK1-4) [37] and three MAPKKK genes $(M A P K K K \alpha, M A P K K K \varepsilon$, and $N P K 1)$ $[31,38,39]$ in tomato have been identified. The three gene families that involved in MAPK cascade have never been systematically investigated in tomato except in our recent report on the MAPK gene family [11]. Taking advantage of the available tomato genome database, we performed a genome-wide search for the homologues of the MAPKK and MAPKKK families in tomato. Detailed information on the genomic structures, chromosomal locations, and sequence homologies of these genes is presented in this paper. In addition, the phylogenetic relationships of these gene families in Arabidopsis, tomato, rice, and maize were compared. Finally, the expression profiles of SIMAPKK and SIMAPKKK genes during development and in response to various biotic and abiotic stress treatments were investigated through quantitative real-time reverse transcription PCR (qRT-PCR) analyses.

\section{Materials and Methods}

\section{Searching for MAPKK and MAPKKK family genes}

Predicted tomato peptide sequences were downloaded from the SGN database (http://solgenomics.net/organism/Solanum_ lycopersicum/genome) to construct a local protein database. To identify tomato MAPKK, this database was searched using all known plant MAPKK protein sequences, including 10 AtMAPKKs, 8 OsMAPKKs, 11 GmMAPKKs and 11 PtMAPKKs, as query sequences downloaded from NCBI (http://ncbi.nlm.nih. gov), TAIR (http://www.arabidopsis.org), and a rice genome database (http://ftp.ncbi.nih.gov/genbank/genomes/Eukaryotes/ plants/Oryza sativa/). Similarly, for the tomato MAPKKK gene family, 80 AtMAPKKK, 75 OsMAPKKK, and 74 ZmMAPKKK protein sequences from Arabidopsis, rice, and maize were used as query sequences to search against the tomato genome database $[7,20,21]$. The search was carried out using BLASTP, and 50\% identity was used as the threshold for the sequences obtained from BLAST analysis. Self BLAST of the sequences was carried out to remove redundancies. The putative functional domains of all the sequences were detected by BLASTP of NCBI (http://blast.ncbi. nlm.nih.gov), and identified using the Pfam program under a default E-value level (0.01) (http://www.Pfam.sanger.ac.uk/) and the SMART database (http://smart.embl-heidelberg.de/). Sequences without known conserved domains of the MAPKK or MAPKKK gene families were excluded from further analysis. Finally, predictions of MAPKK and MAPKKK sequences were further verified with gene structure, EST, and unigene analyses. Furthermore, the full-length cDNA sequences of predicted MAPKKs and MAPKKKs in tomato were identified by BLASTN against the Kazusa Full-length Tomato cDNA Database (http://www.pgb. kazusa.or.jp/kaftom/blast.html). The isoelectric point (pI) of the MAPKK and MAPKKK proteins was predicted using Compute $\mathrm{pI} / \mathrm{Mw}$ software (http://www.expa sych/tools/pitool.html). Subcellular localization prediction of each of these family genes was carried out using the CELLO v2.5 server (http://cello.life.nctu.edu. tw/) [40].

\section{Multiple sequence alignment and phylogenetic analysis}

Multiple sequence alignment for all the MAPKKs and MAPKKKs in Arabidopsis, rice, maize, and tomato was generated using ClustalX v1.81 [41]. PlantsP (http://plantsp.genomics. purdue.edu/index.html) was used to scan the motifs and domains of these kinase protein sequences. Phylogenetic analysis was performed using MEGA 4.1 program by the neighbor-joining (NJ) method [42], and a bootstrap test was carried out with 1000 interactions based on the full-length protein sequences.

\section{Cis-element analysis of putative promoter regions of MAPKK and MAPKKK genes}

To investigate cis-elements in the promoter regions of MAPKK and MAPKKK genes, $2000 \mathrm{bp}$ of the genomic DNA sequences upstream of the transcriptional start site of each MAPKK and MAPKKK gene were chosen. These sequences were used to search against the PLACE database (http://www.dna.affrc.go.jp/ PLACE/) to find the putative cis-regulatory elements.

\section{Mapping MAPKK and MAPKKK genes on chromosomes and gene duplications}

To determine the location of tomato genes on chromosomes, the nucleotide sequences of all these genes were further used as query sequences for BLASTN search against SGN Tomato Whole Genome Scaffold data (2.30) (http://www.sgn.cornell.edu/tools/ blast/). Finally, the locations of these genes in tomato were detected. Synteny analysis of the SIMAPKK and SIMAPKKK genes was performed online using PGDD (http://chibba.agtec. uga.edu/duplication/) [43]. Tandem duplications were defined as genes located within five loci of each other [44].

\section{Plant materials, growth conditions, and treatments}

Tomato (S. lycopersicum L.) cv. Micro-Tom plants used for expression analysis from the Tomato Genetics Resource Center (University of California, Davis, USA) were grown in growth chambers at $26 \pm 1{ }^{\circ} \mathrm{C}$ at $40 \%$ to $50 \%$ relative humidity with a photoperiod of $14 \mathrm{~h}$ light/10 h dark. Three-week-old seedlings with three fully opened leaves were used for all abiotic and biotic treatments. The leaves, stems, roots, flower buds (1 d before 


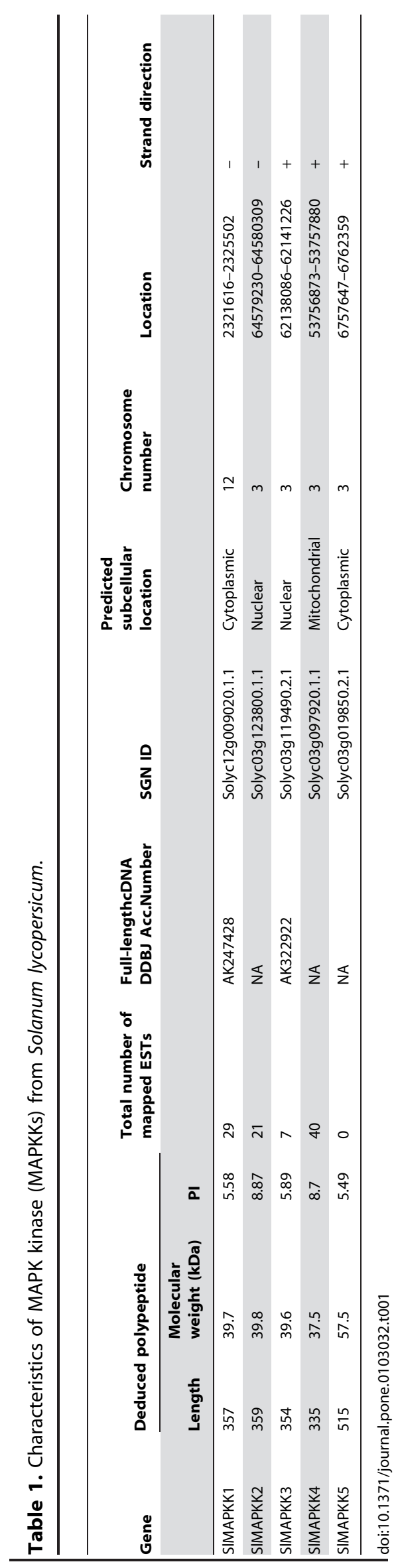

flowering), and fruits (10 d after pollination) were collected from flowering plants. All the samples were frozen in liquid nitrogen immediately and stored at $-75^{\circ} \mathrm{C}$ until RNA isolation.

Heat and cold stresses were produced by incubating the seedlings at $37 \pm 1^{\circ} \mathrm{C}$ and $4 \pm 1{ }^{\circ} \mathrm{C}$ for $2 \mathrm{~h}$, respectively. Drought stress was initiated by withholding water supply to three-week-old seedlings after they were fully watered. Leaves were harvested after withholding water for $7 \mathrm{~d}$ when the leaves started to curl because of drought stress. Salt stress was produced by adding $200 \mathrm{mM}$ sodium chloride to the planter box for $3 \mathrm{~h}$. Control seedlings were grown at $26 \pm 1{ }^{\circ} \mathrm{C}$ with normal irrigation.

Biotic stress treatment was carried out using Pseudomonas syringae pv. tomato DC3000 cultivated in King's B medium. The cells were pelleted, resuspended, and diluted in $10 \mathrm{mM} \mathrm{\textrm {MSO } _ { 4 }}$ and $0.02 \%$ Silwet- 77 to a concentration of $2 \times 10^{5} \mathrm{CFU} \mathrm{m}^{-1}$ to $8 \times 10^{6} \mathrm{CFU} \mathrm{ml} \mathrm{m}^{-1}$. The plants were spray-inoculated until leaf surfaces were uniformly wet. Meanwhile, the control seedlings were sprayed with $\mathrm{ddH}_{2} \mathrm{O}$ with $10 \mathrm{mM} \mathrm{MgSO}_{4}$ and $0.02 \%$ Silwet-77 without bacterial strains. After inoculation, the tomato plants were incubated at $26 \pm 1{ }^{\circ} \mathrm{C}$ in $60 \%$ relative humidity with a $14 \mathrm{~h}$ photoperiod for the duration of the experiment. The samples were collected $2 \mathrm{~h}$ after treatment.

For hormone treatments, the seedling leaves were sprayed with $100 \mathrm{mM}$ indole-3-acetic acid (IAA) or $100 \mathrm{mM}$ salicylic acid (SA), and sampled at $0,1,2,4,8$, and 16 h intervals [45].

Each experiment was repeated three times, and 20 seedlings were used in each replication of each treatment.

\section{RNA extraction and qRT-PCR expression analysis}

The total RNA was extracted using TRIZOL reagent (Invitrogen, Germany) according to the manufacturer's instructions. The first cDNA strand was generated using a Takara Reverse Transcription System (Japan) following the manufacturer's protocol. A maximum of $1 \mu \mathrm{g}$ of RNA was used for each reverse-transcription reaction, and a gDNA eraser in the kits was used to eliminate DNA to prevent DNA contamination. qRTPCR techniques were employed to characterize the gene expression profiles of SIMAPKKs and SIMAPKKKs using the primer pairs designed by Applied Biosystems Primer Express software (Table S1). To ensure the specificity of each primer to its corresponding gene, the primers were submitted to the tomato genome database for BLAST search. All non-specific primers that show more $50 \%$ percent sequence similarity to multiple regions were eliminated and redesigned to minimize potential non-specific PCR amplification. Thus, the results from real-time PCR analysis might represent the expression pattern of a specific MAPKK or MAPKKK gene. Real-time PCR analyses were carried out according to the description by $\mathrm{Wu}$ et al. [46]. Two biological and at least three technical replicates for each sample were obtained in the real-time PCR machine (BIO-RAD CFX96, USA). To normalize the total amount of cDNA in each reaction, the tomato SlUbi3 (accession number X58253) gene was coamplified as an endogenous control to calibrate relative expression. The $\mathrm{C}_{\mathrm{t}}$ method of relative gene quantification recommended by Applied Biosystems (PE Applied Biosystems, USA) was used to calculate the expression levels of different treatments. Student's ttest was used to determine the statistical significance of the differential expression patterns between treatments. A heatmap was generated by matrix2png using the relative expression data of each SIMAPKK and SIMAPKKK gene [47]. 

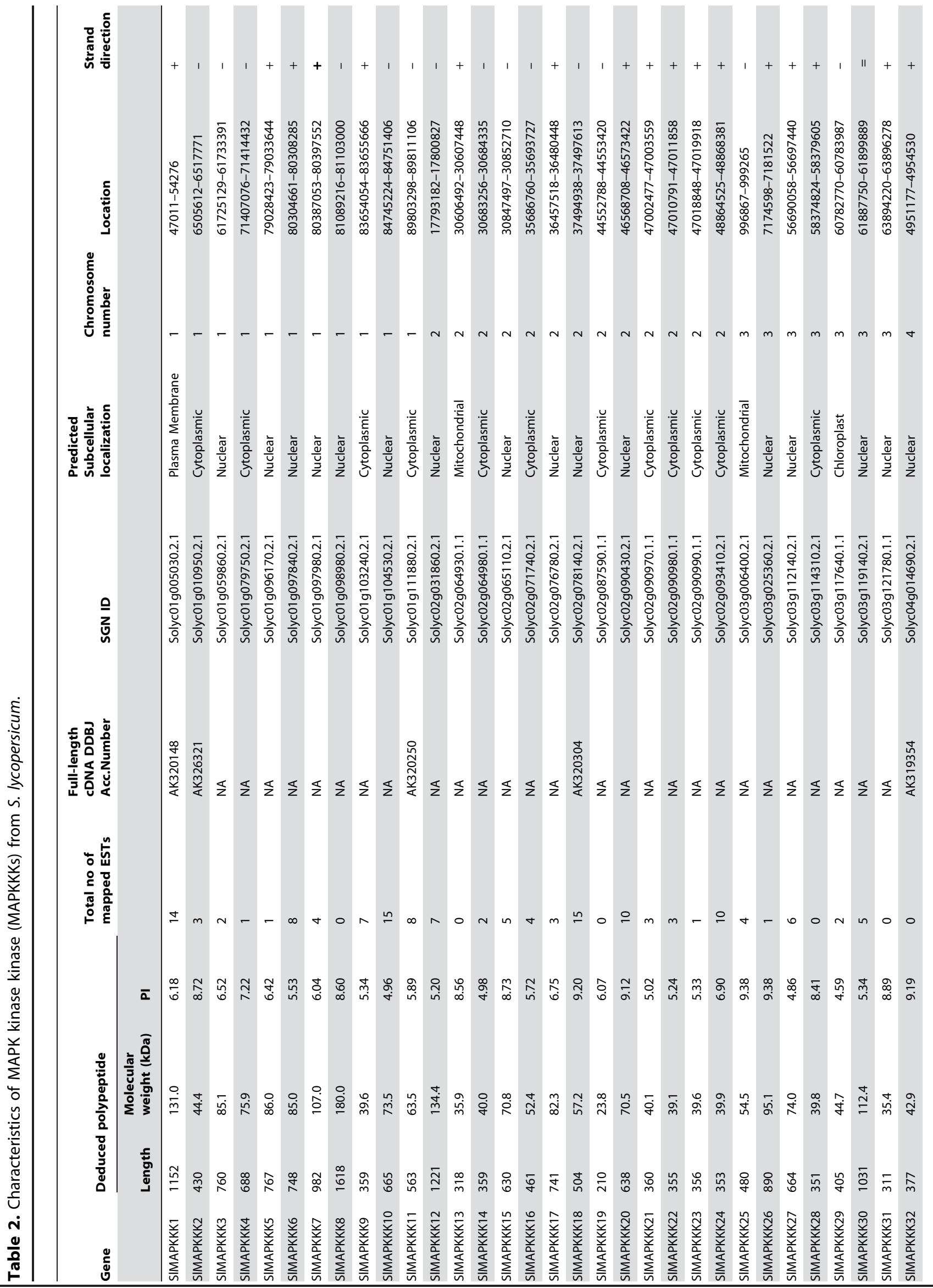


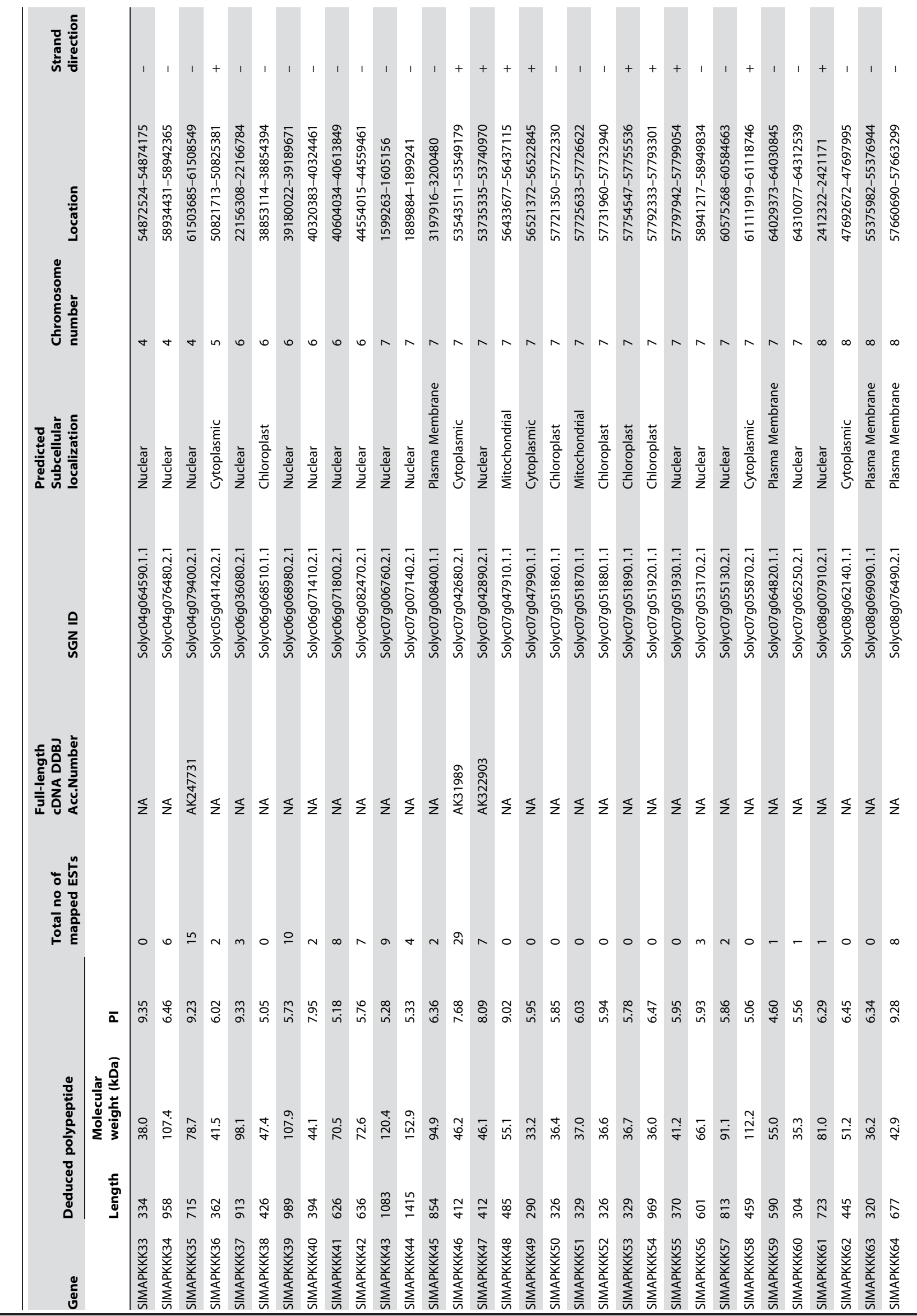




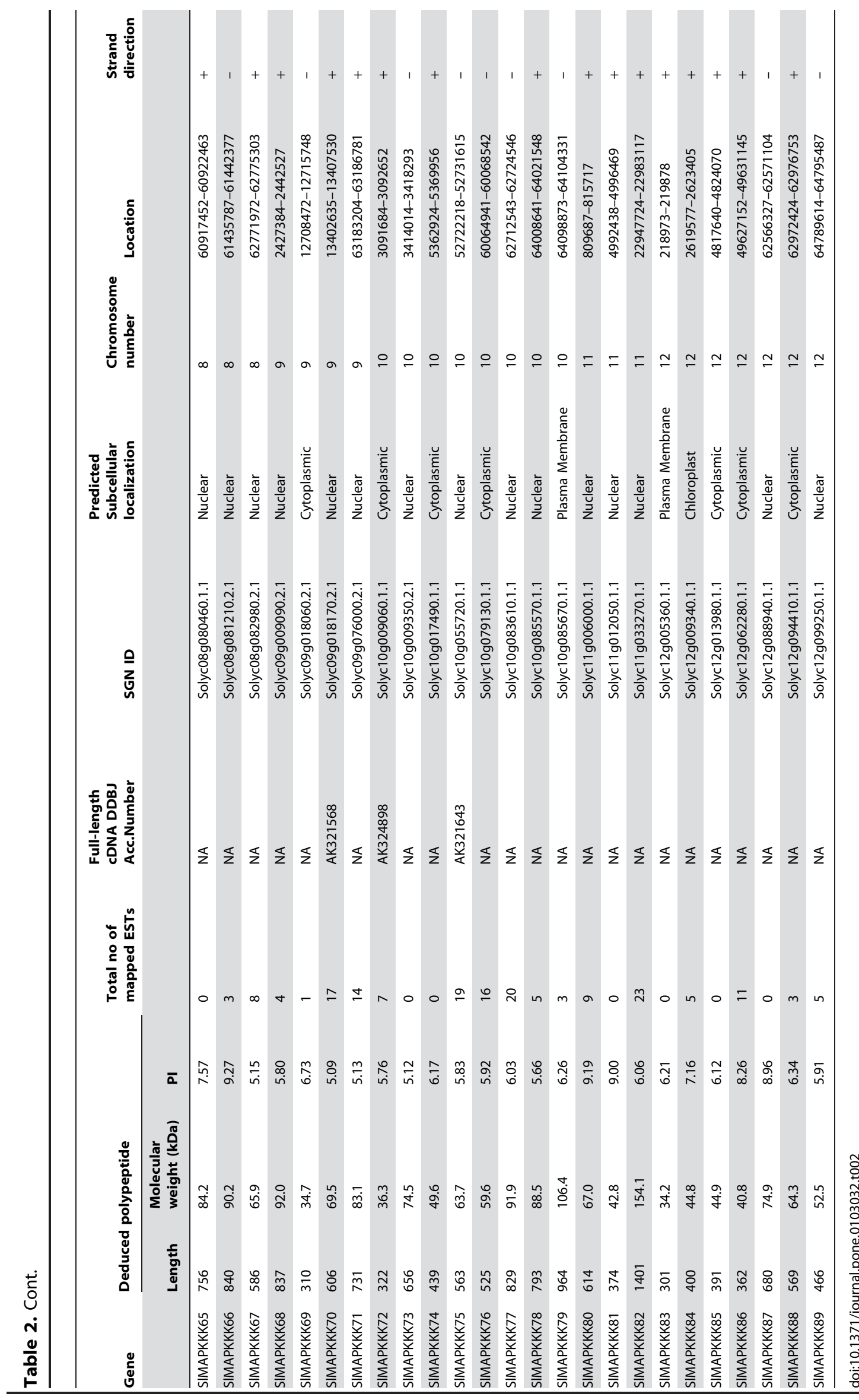



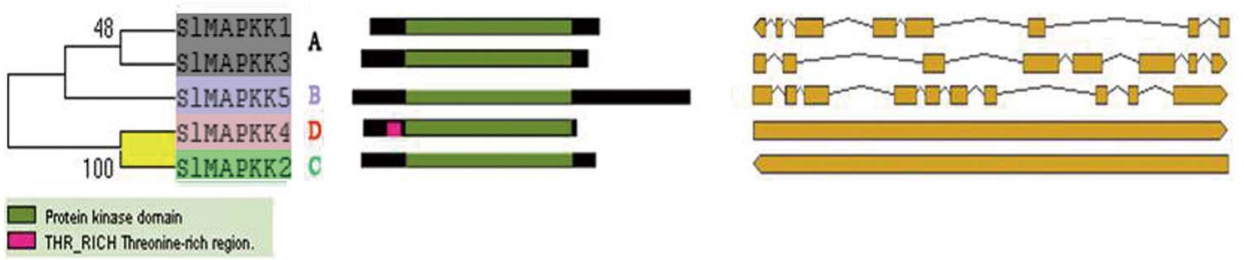

Protein kinase domain

THR_RICH Threonine-rich region.

Figure 1. Phylogenetic analysis (left), domain organization (middle) and exon-intron structures (right) of tomato MAPKKs. The unrooted phylogenetic tree was generated using MEGA4.1 program by the neighbor-joining method. Bootstrap supports from 1000 replicates are indicated at each branch. The gene names of each subfamily are indicated with the same color. The domain organizations are analyzed by scanning of the protein sequences for the presence of known motifs and domains using PlantsP. The exon-intron organization of corresponding SIMAPKK genes is represented by yellow boxes and lines, respectively.

doi:10.1371/journal.pone.0103032.g001

\section{Results and Discussion}

Identification and sequence analysis of MAPKK and MAPKKK genes in tomato

The published tomato genome database enables the genomewide analysis of the MAPKK and MAPKKK gene families in tomato [48]. To find all the members of these two families, BLASTP searches against a local database built using protein sequences were performed using these sequences, which contained 40 MAPKKs from four species, including Arabidopsis, rice, soybean, and Populus trichocarpa, and 155 MAPKKKs from
Arabidopsis, rice, and maize. Only the members with above $50 \%$ identity were collected. Redundant sequences were removed manually. Thus, we found eight candidates for SIMAPKKs and 103 candidates for SIMAPKKKs. The candidate sequences were further evaluated by identifying the putative functional domains of through NCBI BLASTP (http://blast.ncbi.nlm.nih.gov/). The sequences without the relevant domains or conserved motifs were removed. After multiple cycles of these analyses, we identified five SIMAPKKs and 89 SIMAPKKKs from the currently available tomato. We completed EST hits and a full-length cDNA search to verify their existence (Tables 1 and 2). The existence of all
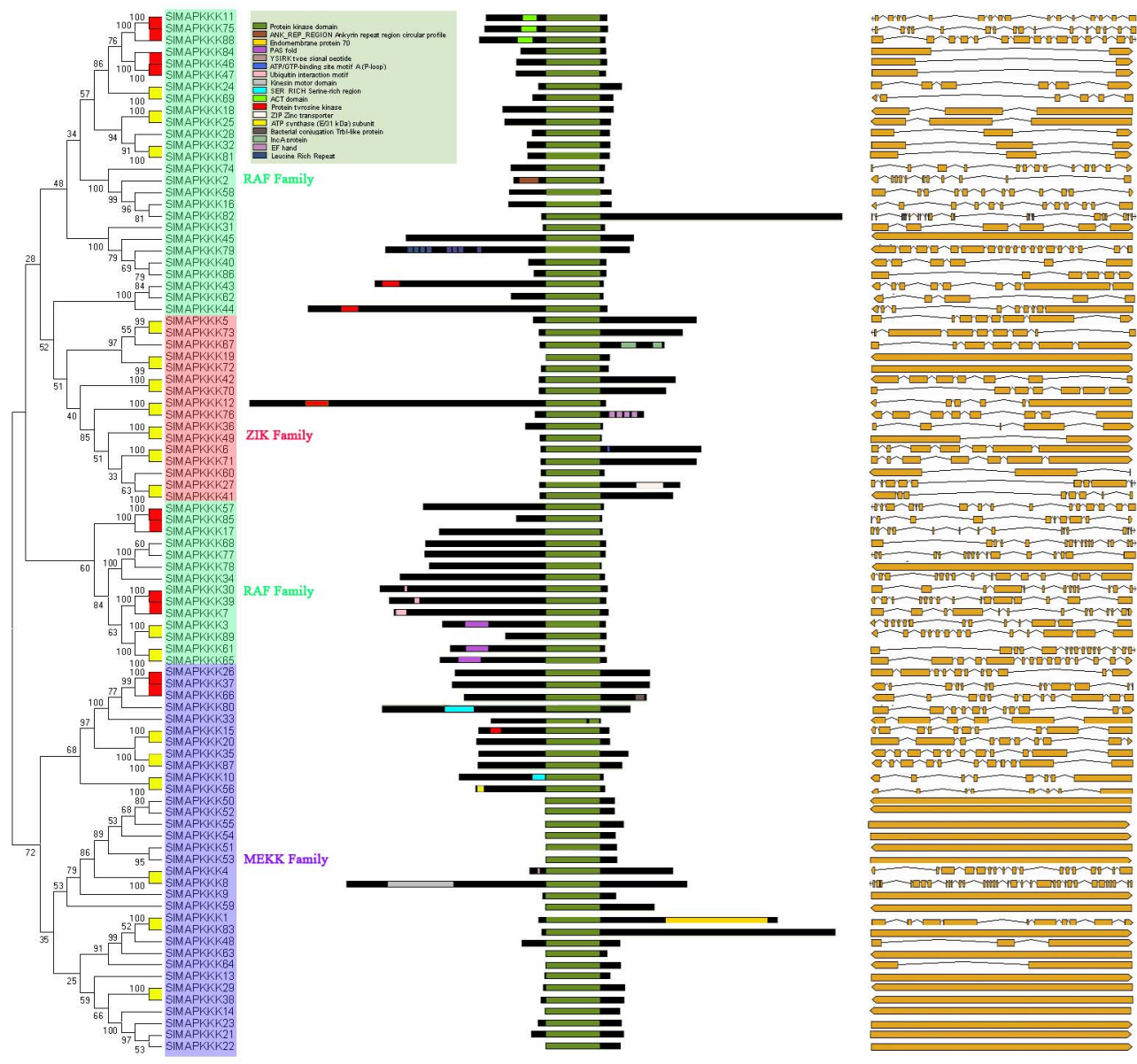

Figure 2. Phylogenetic analysis (left), domain organization (middle) and exon-intron structures (right) of 89 SIMAPKKKs in tomato. For other details, see Figure 1.

doi:10.1371/journal.pone.0103032.g002 


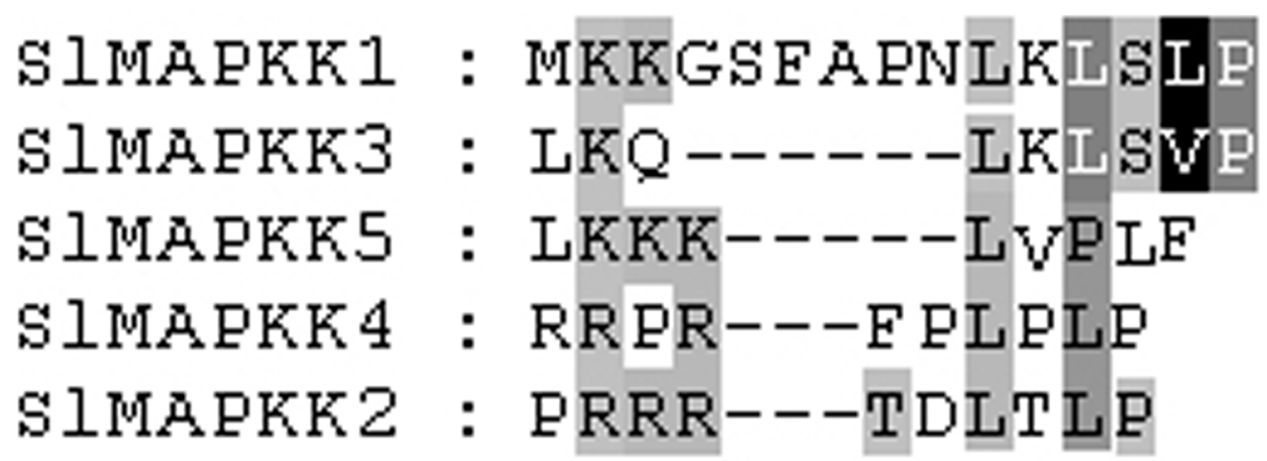

Figure 3. Alignment of SIMAPKK proteins in tomato. The highlighted part shows the conserved signature motif obtained with the ClustalX program.

doi:10.1371/journal.pone.0103032.g003

MAPKKs was supported by EST hits except SlMAPKK5, and two out of five MAPKKs were found in full-length cDNA sequences. The existence of MAPKKK family genes was also supported by EST hits, whereas only 11 out of 89 SIMAPKKKs were found in full-length cDNA sequences. Given that no standard nomenclature is followed for MAPKKKs in plant species, we named them sequentially based on their distribution on chromosomes $[5,20]$.

The polypeptide lengths of the MAPKK genes ranged from 335 aa to 515 aa, and their predicted molecular weights ranged from $37.5 \mathrm{kD}$ to $57.5 \mathrm{kD}$. The predicted $\mathrm{pI}$ has a range of 5.49 to 8.7 . However, the polypeptide lengths of the MAPKKK genes ranged from 290 aa to 1618 aa, and their predicted molecular weights ranged from $23.8 \mathrm{kD}$ to $180 \mathrm{kD}$. The theoretical $\mathrm{pI}$ has a range from 4.59 to 9.38 (Tables 1 and 2).

The MAPKK genes were predicted to be localized in the cytoplasm, nucleus, and mitochondria. Similarly, most of the
MAPKKK genes were predicted to be localized in the cytoplasm, nucleus, and mitochondria, and others were predicted to be localized in the plasma membrane and chloroplast (Tables 1 and 2).

Phylogenetic relationship, conserved domain, and gene structure analysis

To further characterize the MAPKKs and MAPKKKs from tomato, the kinase domains of tomato were aligned using ClustalW and analyzed using MEGA4. Unrooted phylogenetic trees were generated from the alignment of the full-length protein sequences of all five SIMAPKKs and 89 SIMAPKKKs by the NJ and ME methods, and showed similar topologies with only minor modifications at deep nodes. Similar to those in Arabidopsis and rice $[3,4]$, five MAPKK genes in tomato formed four groups (groups A-D) (Fig. 1). Consistent with previous reports on

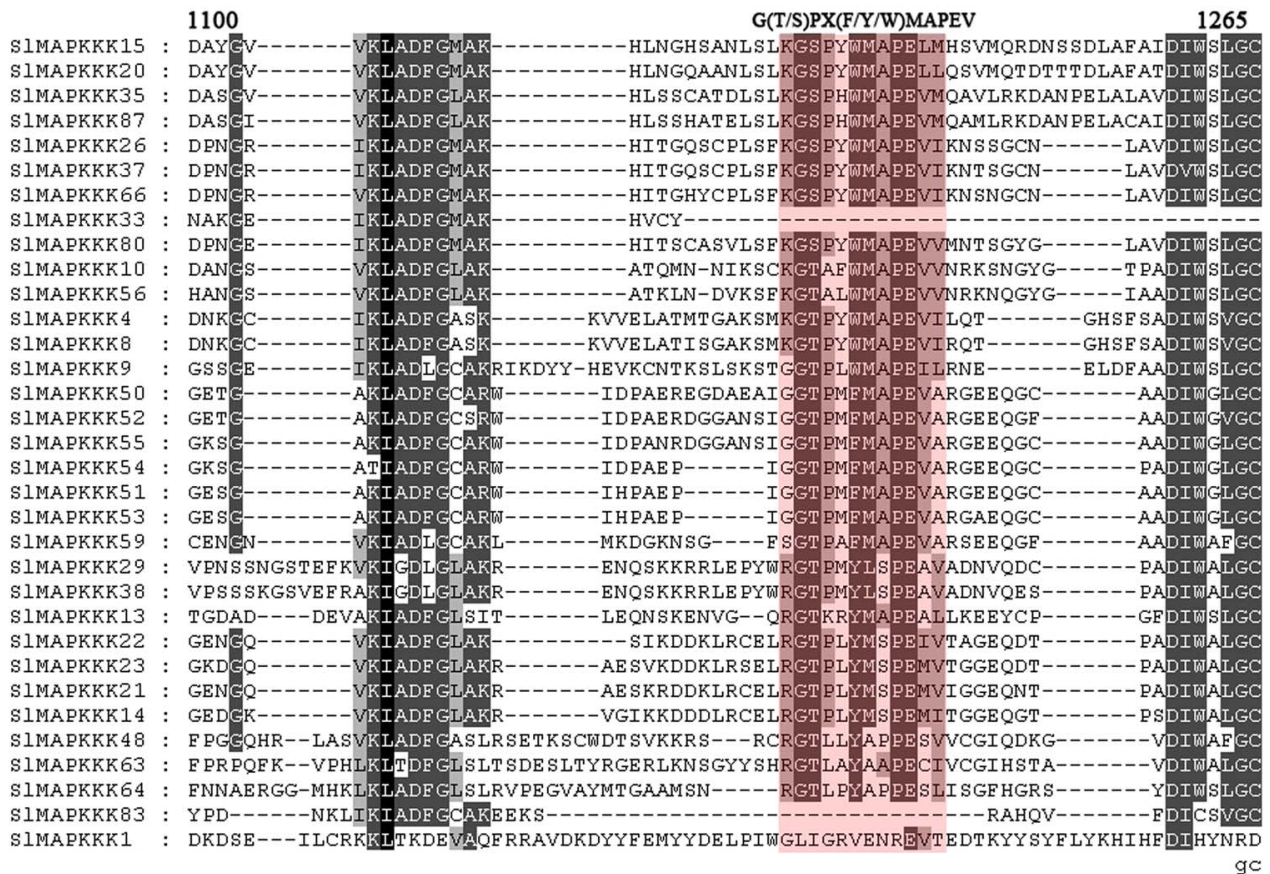

Figure 4. Alignment of MEKK-like SIMAPKKK proteins obtained with the ClustalX program. The highlighted part shows the conserved signature motif.

doi:10.1371/journal.pone.0103032.g004 


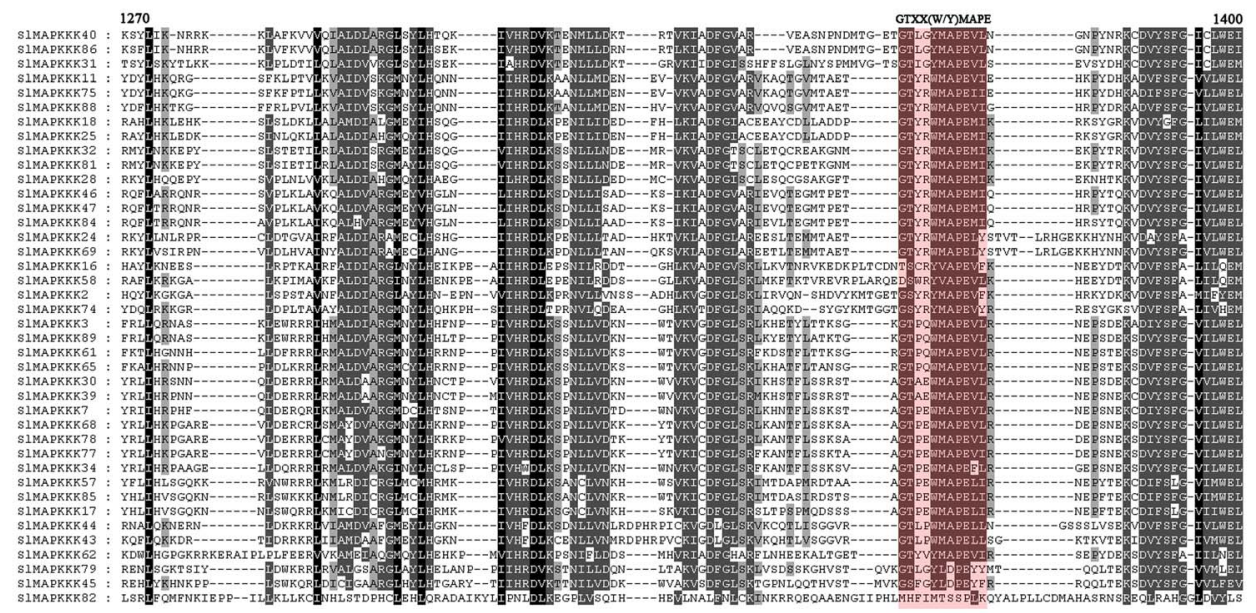

Figure 5. Alignment of Raf-like SIMAPKKK proteins obtained with the ClustalX program. The highlighted part shows the conserved signature motif.

doi:10.1371/journal.pone.0103032.g005

Arabidopsis, rice, and maize [4,20,21], 89 SIMAPKKKs were divided into three categories, including 33 MEKK members, 16 ZIK members, and 40 RAF members (Fig. 2).

Conserved domain analysis showed a kinase domain in all the MAPKKs and MAPKKKs. In the SIMAPKKK family, most of the Raf family proteins contained a C-terminal kinase domain and long N-terminal regulatory domain except for SlMAPK82. By contrast, the majority of the ZIK members had an N-terminal kinase domain except for SlMAPK12. Protein tyrosine regions were distributed across different subfamily members. A ubiquitininteraction motif and ACT domain functioning in the regulation of a wide range of metabolic enzyme activities were found only in the RAF subfamily (Fig. 2), which is consistent with the previous findings in rice and Arabidopsis [7,20].

Based on the predicted sequences, tomato MAPKK and MAPKKK gene structures were mapped. SlMAPKK1 and SlMAPKK3 belonging to group A contained eight exons and seven introns, but MAPKK genes from groups $\mathrm{C}$ and D usually contained no intron (Fig. 1). The gene structures of MAPKKKs were highly divergent, even in the same subfamily. The intronexon patterns of these genes showed no obvious similarity among the members even in the same group (Fig. 2). However, when comparing the intron-exon organization with phylogenetic analysis of these genes, we found that there was a relatively good correlation between intron conservation and phylogenetic relationships. Those genes clustering together on the phylogenetic trees often had similar intron-exon patterns (Figs.2). For example, SlMAPKKK46, SlMAPKKK47, and SlMAPKKK84 clustered with very high bootstrap $(100 \%)$ on the phylogenetic tree. Meanwhile, all of them contained only one intron (Figs. 1 and 2).

\section{Sequence alignments of conserved motifs}

All the identified MAPKK genes from Arabidopsis, rice, and poplar contain 11 catalytic subdomains $[4,49]$. MAPKKs were also featured by a putative K/R-K/R-K/R-X (1-6)-L-X-L/V/I domain as a docking region. This conserved motif could also be found in most tomato MAPKK proteins (Fig. 3).

The plant MAPKKK gene family was formed by three subfamilies, each of which contains signature sequences or motifs different from those in the other two subfamilies [7]. In this study, a conserved motif $\mathrm{G}(\mathrm{T} / \mathrm{S}) \mathrm{PX}(\mathrm{F} / \mathrm{Y} / \mathrm{W}) \mathrm{MAPEV}[20]$ was found in all 33 putative MEKK genes except SlMAPKKK1, SlM $A P K K K 33$, and SlMAPKKK83, further confirming that they belonged to the MEKK subfamily (Fig. 4). The RAF family is the

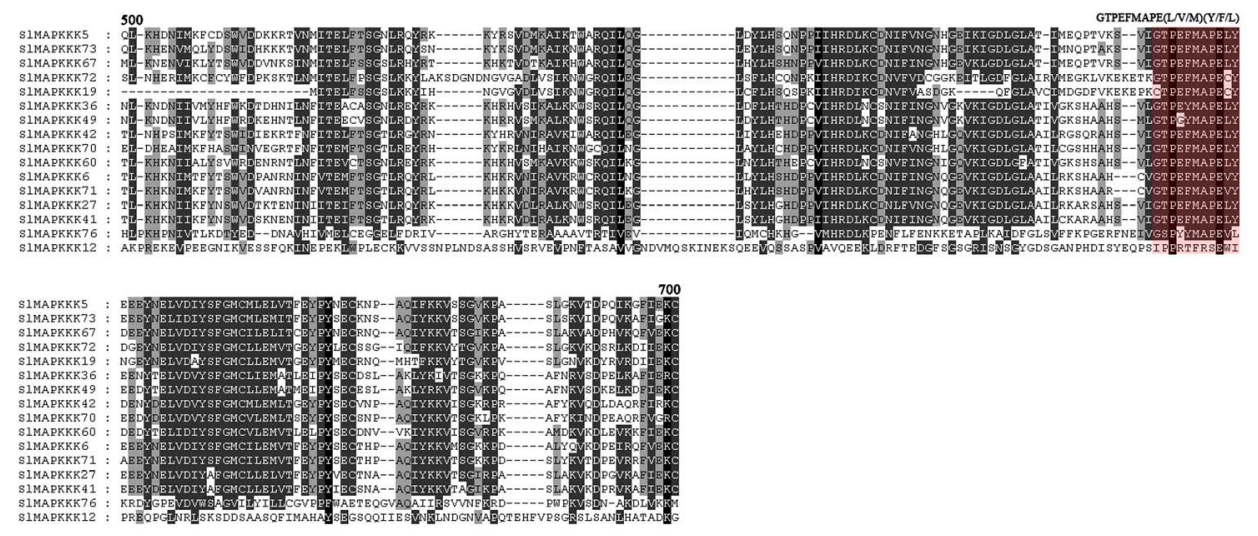

Figure 6. Alignment of ZIK-like SIMAPKKK proteins obtained with the ClustalX program. The highlighted part shows the conserved signature motif.

doi:10.1371/journal.pone.0103032.g006 


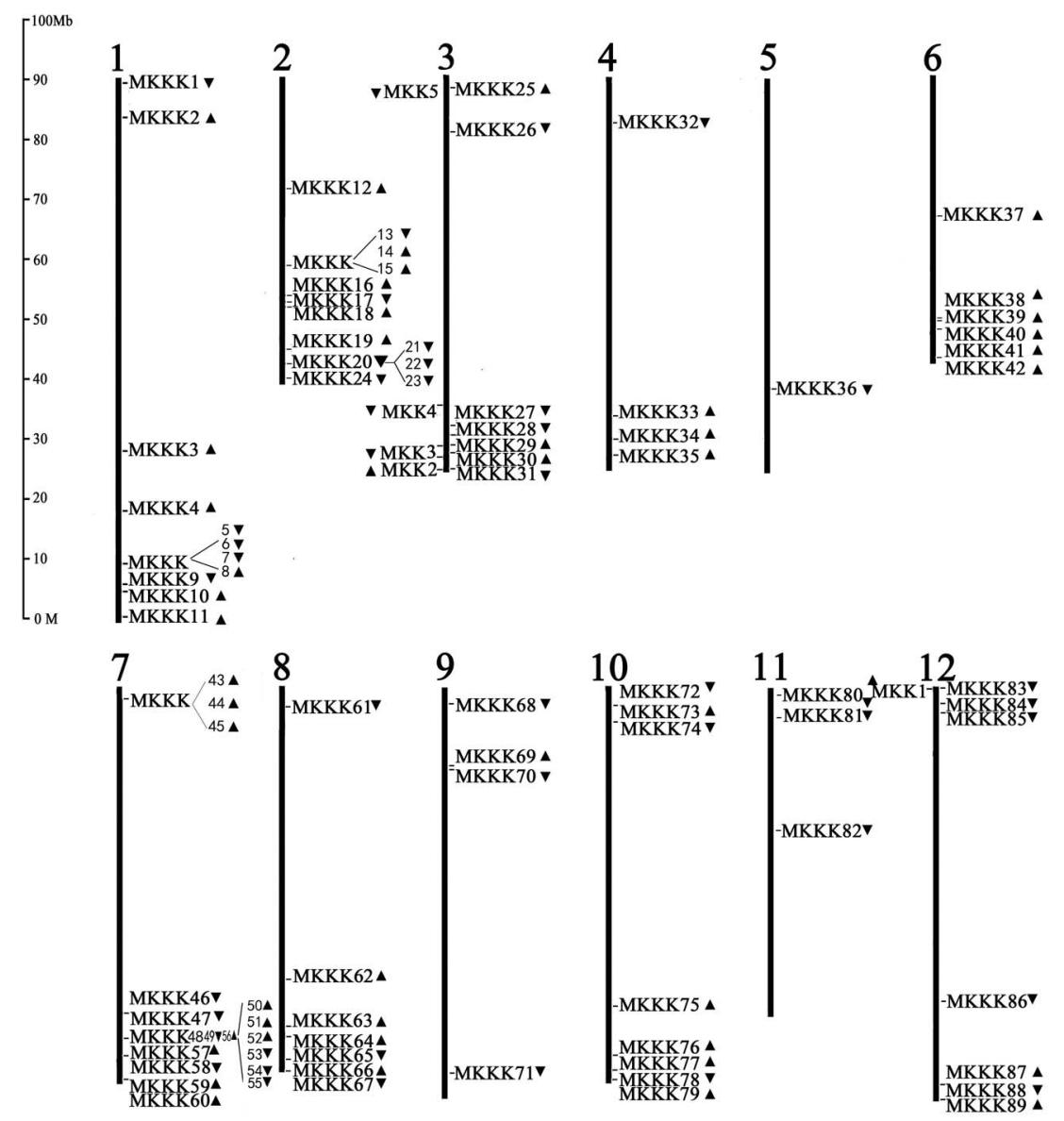

Figure 7. Chromosomal distribution of SIMAPKKs and SIMAPKKKs genes in tomato genome. The names of each tandem duplicated gene cluster of the two families were indicated with black rectangles. The triangles indicate the upward or downward direction of transcription. doi:10.1371/journal.pone.0103032.g007

largest subfamily in tomato and other reported species with a conserved signature GTXX (W/Y) MAPE in its kinase domain across the members [20]. In tomato, this signature was also found in all the members of the RAF family except SIMAPK83, strongly supporting their identity as members of the RAF subfamily (Fig. 5). The characteristic feature of the ZIK family consists of a conserved signature GTPEFMAPE (L/V/M) (Y/F/L) across the members [20]. Sixteen MAPKKKs out of 89 members had ZIK specific signatures (Fig. 6).

\section{Chromosomal mapping and gene duplication}

The chromosomal locations and transcription directions of tomato $M A P K K$ and $M A P K K K$ genes were determined and demonstrated using BLASTN analysis on tomato WGS chromosomes. Interestingly, five SIMAPKKs were distributed on chromosomes 3 and 12 (Fig. 7). Four of them were located on chromosome 3, and the other one was located on chromosome 12. Although the SIMAPKKK family genes were distributed over all the 12 chromosomes (Fig. 7), the number in each chromosome differed, ranging from one (chromosome 5) to 18 (chromosome 7).

Gene duplication events have an important function in the amplification of gene family members in tomato genome. Gene families can arise through the tandem amplification or segmental duplication of chromosomal regions [50]. In this study, no tandem duplicated gene pairs and segmental duplicate families were found in the SIMAPKK gene. In the SIMAPKKK gene family, we found

Table 3. The numbers of SIMAPK, SIMAPKK, and SIMAPKKK in Arabidopsis, rice, tomato, and maize.

\begin{tabular}{|c|c|c|c|c|c|c|}
\hline \multirow[t]{2}{*}{ Species } & \multirow{2}{*}{ MAPK } & \multirow{2}{*}{ MAPKK } & \multicolumn{3}{|c|}{ MAPKKK } & \multirow{2}{*}{ Total number of MAPKKKs } \\
\hline & & & MEKK & ZIK & RAF & \\
\hline Arabidopsis & 20 & 10 & 21 & 11 & 48 & 80 \\
\hline tomato & 16 & 5 & 33 & 16 & 40 & 89 \\
\hline rice & 15 & 8 & 22 & 10 & 43 & 75 \\
\hline maize & 20 & 14 & 22 & 6 & 46 & 74 \\
\hline
\end{tabular}

doi:10.1371/journal.pone.0103032.t003 


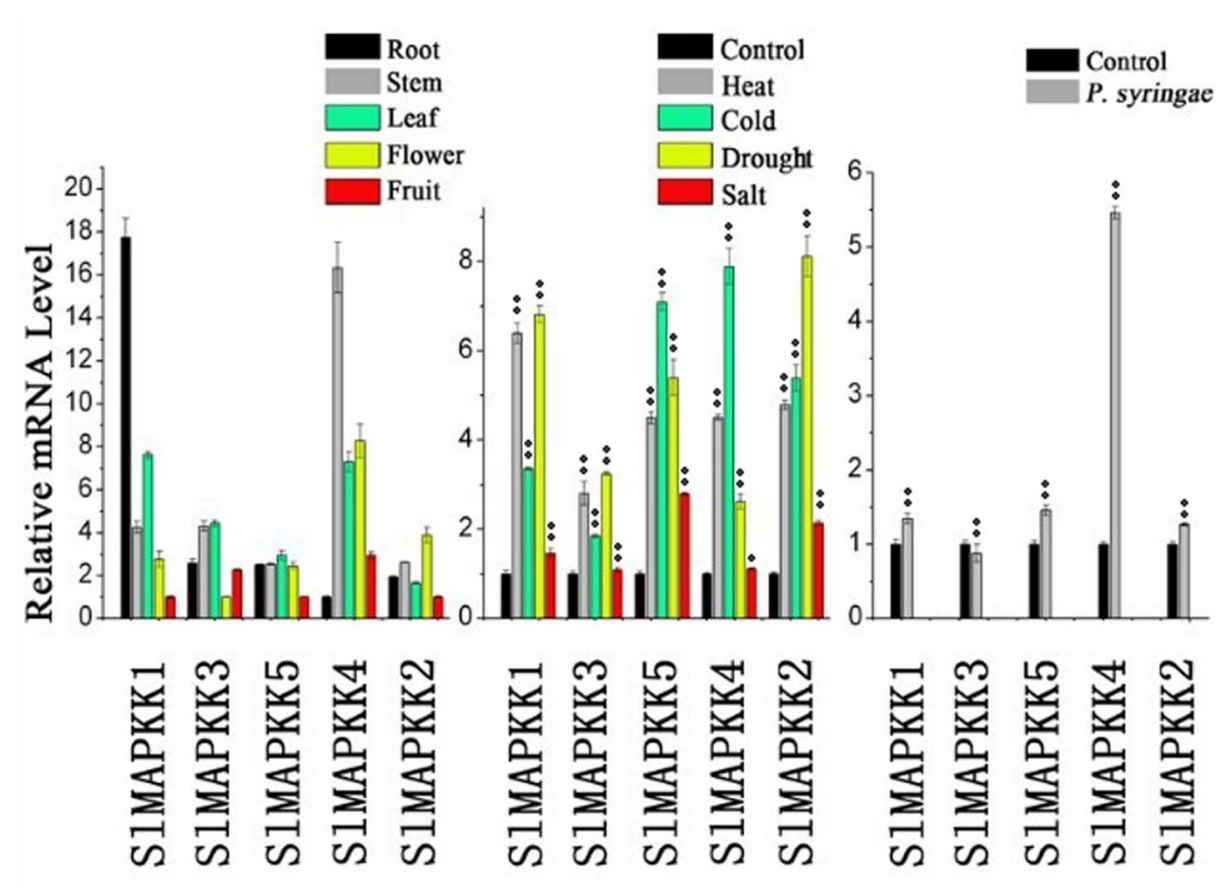

Figure 8. Expression profiles of SIMAPKK family genes in tomato using qRT-PCR analysis. A: transcript levels of all 5 SIMAPKK in different tomato organs including root, stem, leaf, flower buds, and fruit. B: transcript level change of all 5 SIMAPKK genes in tomato seedlings exposed to heat $(\mathrm{H})$, Cold (C), drought (D), salt (S) stresses when compared to control treatment. C: transcript levels of all five SIMAPKK genes in tomato seedlings exposed to Pseudomonas syringes. Data represent the means and standard errors of three independent biological samples. Relative expression levels were normalized relative to a reference gene SIUbi3 (accession number X58253). Asterisks indicate significant differences as determined by Student's t-test $\left({ }^{* P}, 0.05 ; * * P, 0.01\right)$.

doi:10.1371/journal.pone.0103032.g008

two clusters (Fig. 7, red box) and 23 segmental duplications. Synteny analysis further confirmed the segmental duplications among the SIMAPKKK genes. Most of the pairs of segmental duplicates were distributed on different chromosomes. Three pairs were also distributed on the same chromosome. Even though some gene pairs shared high similarity in sequence, such as SlMAPKK2/

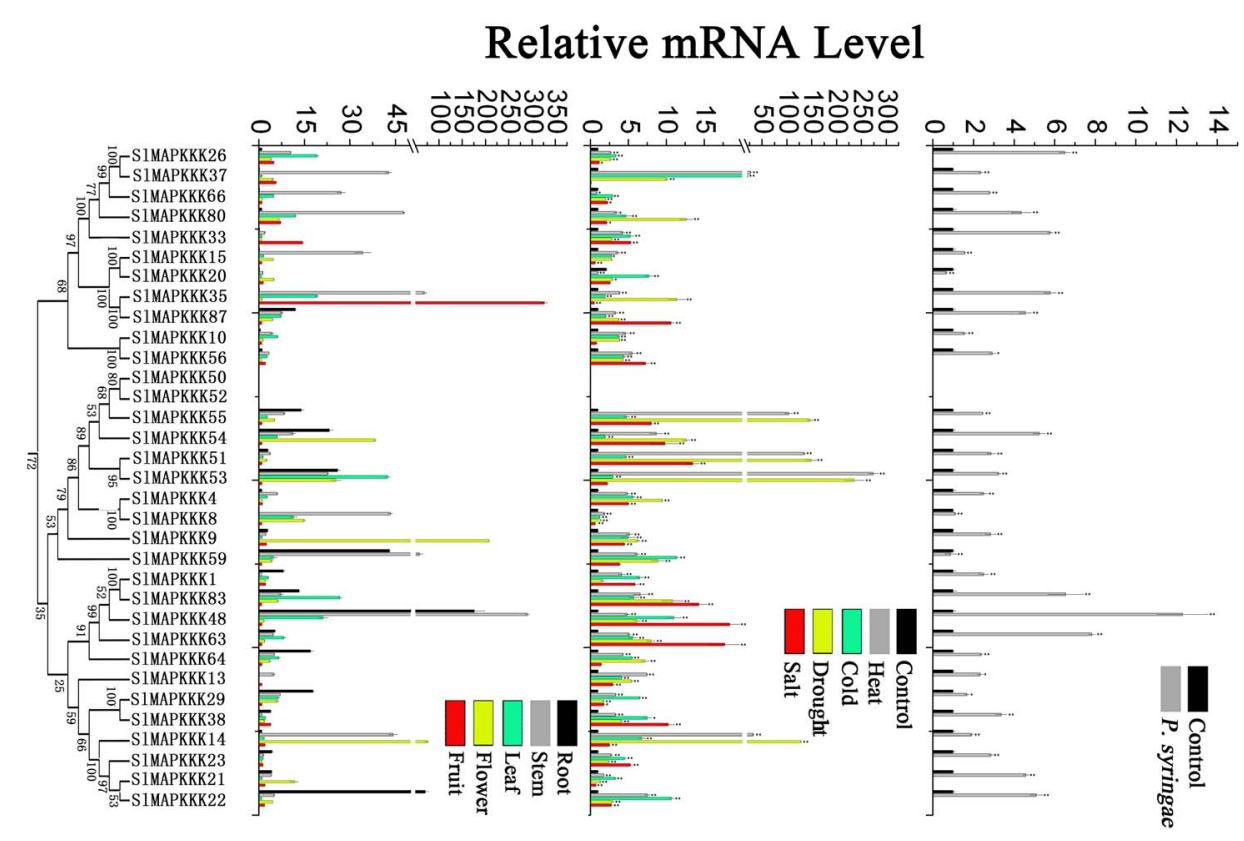

Figure 9. Expression patterns of MEKK subfamily genes in different organs and under abiotic and biotic stress treatment in tomato by $\mathbf{q R T}$-PCR analysis. For other details, see Figure 8 .

doi:10.1371/journal.pone.0103032.9009 

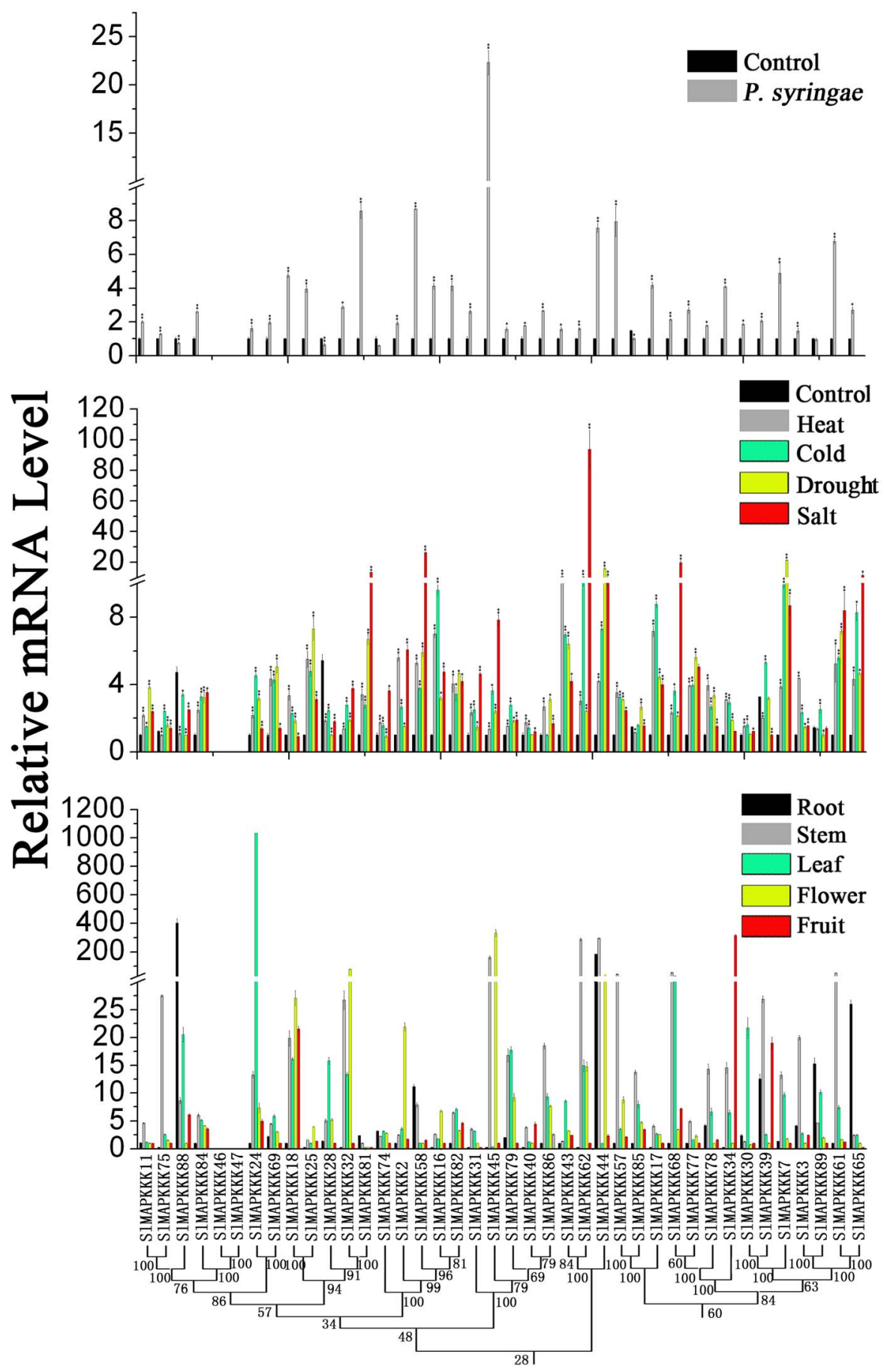

Figure 10. Expression patterns of RAF subfamily genes in different organs and under abiotic and biotic stress treatment in tomato by qRT-PCR analysis. For other details, see Figure 8 . doi:10.1371/journal.pone.0103032.g010

SlMAPKK4, SlMAPKKK1/SlMAPKKK83, SlMAPKKK10/SlM APKKK56, SlMAPKKK57/SlMAPKKK85, and SlMAPKKK7/ SlMAPKKK30/SlMAPKKK39, we found no clear evidence of segmental duplication among them (Fig. S1). Thus, the expansion of the MAPKKK gene families in tomato might be a consequence of whole genome or chromosomal segment duplications. The tandem duplications may have slight affection.
Cis-elements in promoter regions of SIMAPKK and SIMAPKKK genes

Genes responsive to multiple stimuli are closely correlated with cis-regulatory elements in their promoter regions [43]. To further understand transcriptional regulation and the potential function of SIMAPKKs and SIMAPKKKs, cis-elements in their promoter sequences were predicted. Many cis-elements involved in plant growth and resistance were found in the $2 \mathrm{~kb}$ upstream region of tomato SlMAPKK and SlMAPKKK genes using the PLACE 


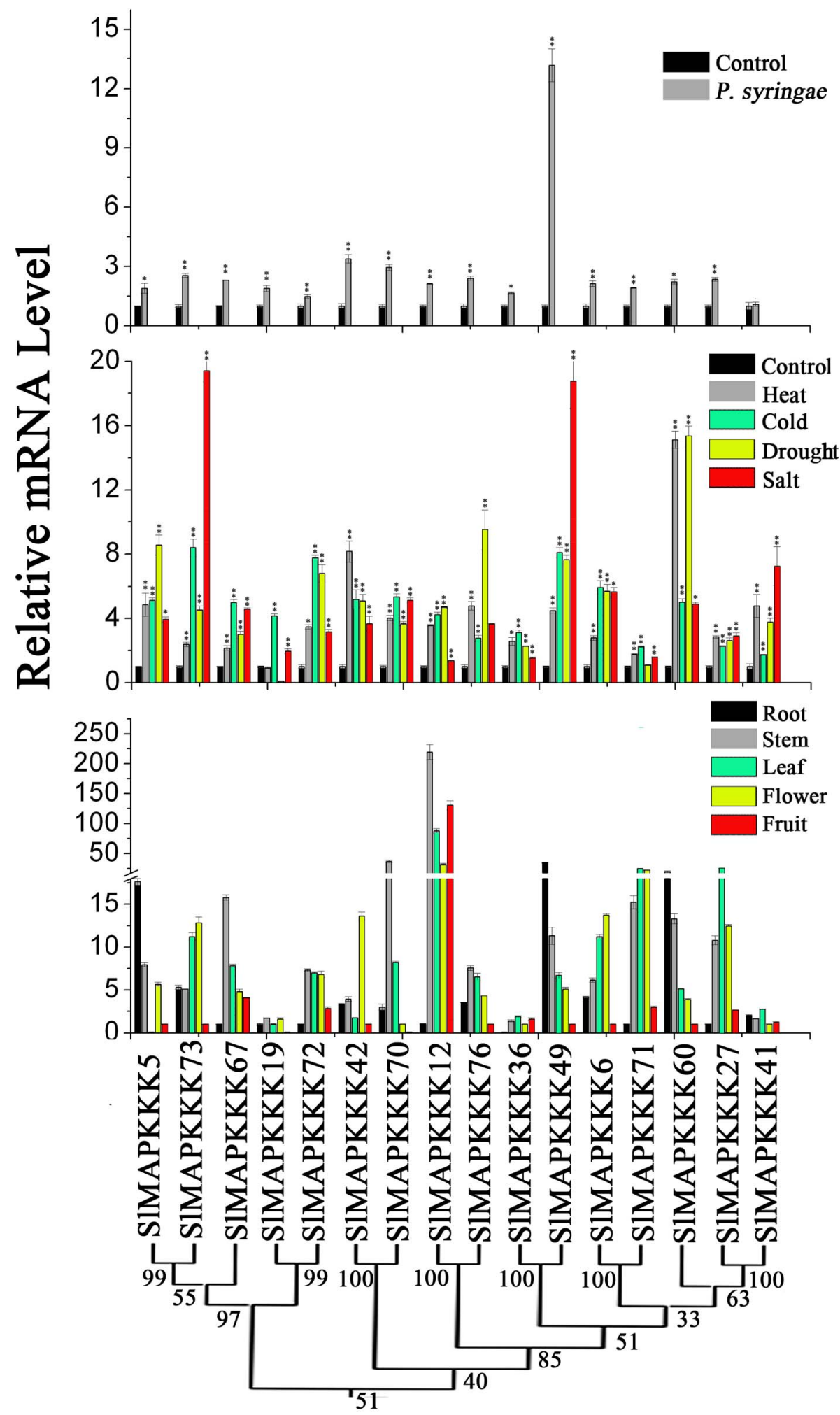

Figure 11. Expression patterns of ZIK subfamily genes in different organs and under abiotic and biotic stress treatment in tomato by qRT-PCR analysis. For other details, see Figure 8 (Left corresponding to upper part; middle corresponding to middle part; Right corresponding to lower part).

doi:10.1371/journal.pone.0103032.g011

database (http://www.dna.affrc.go.jp/PLACE/) (Tables S2 and S3). One salt-stress (S000453), one heat-stress (S00030), one coldstress (S000407), one wound-stress (S000457), three drought- stresses (S000176, S000407, and S000409), and disease resistance (S000024)-related cis-elements were all found in the promoter regions of both SlMAPKKs and SlMAPKKKs. Moreover, auxin 

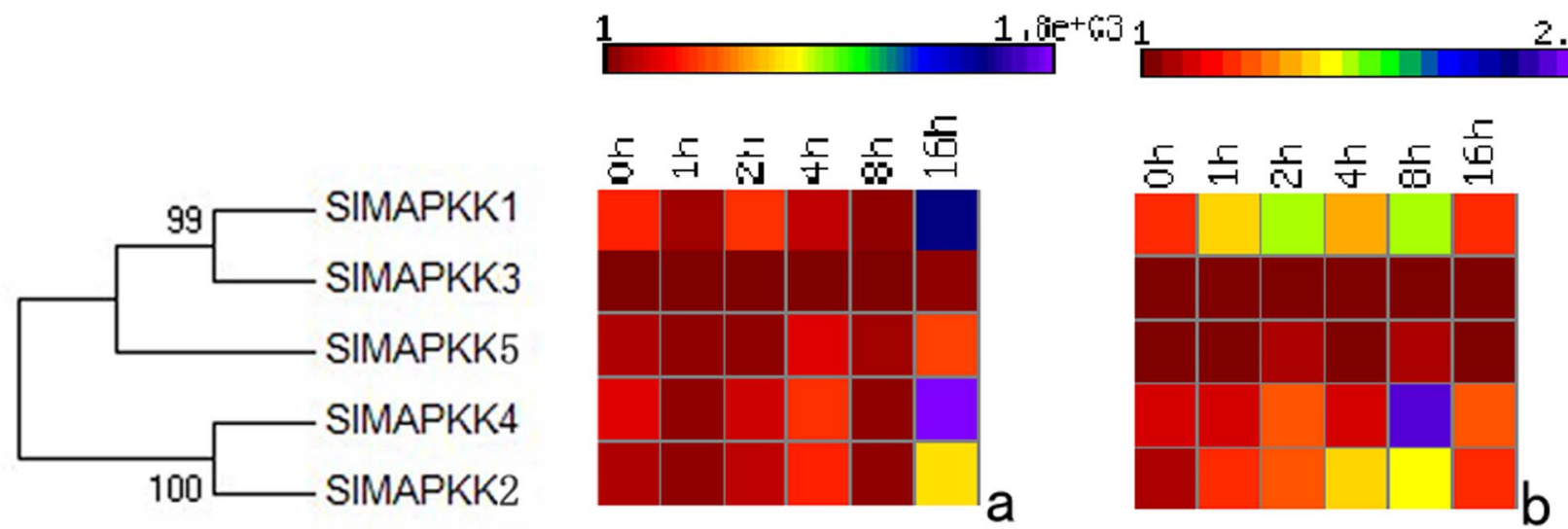

Figure 12. Heat map shows the real-time quantitative RT-PCR (qRT-PCR) analysis results of SIMAPKK genes with exogenous IAA (left) and SA (right) treatments.

doi:10.1371/journal.pone.0103032.g012

(S000273), GA (S000259), ABA (S000292), and ET (S000037) signaling transduction-related cis-elements were found in most of the detected sequences (Tables S2 and S3). These results suggest that most SIMAPKKs and SIMAPKKKs may participate in tomato development and in response to stressful environments.

\section{Evolutionary patterns and divergence of MAPKK and MAPKKK genes in plants}

To further investigate the evolutionary relationships of MAPKK and MAPKKK proteins, we compared these two gene families between two monocotyledonous (maize and rice) and two dicotyledonous plants (Arabidopsis and tomato). Unrooted phylogenetic trees were constructed based on 37 MAPKK and 318 MAPKKK sequences (Figs. S2 and S3). The numbers of MAPKKs and MAPKKKs in different species are indicated in Table 3. The AtMAPKKs and AtMAPKKKs were downloaded from TAIR. The OsMAPKKs and OsMAPKKKs were downloaded from KOME. The ZmMAPKKKs were downloaded from NCBI. Given that the ZmMAPKKs have not been reported systematically, we identified and analyzed MAPKK family genes in maize using the same method for identifying tomato SlMAPKKs (Table S4, Figs. S4 and S5).

Similar to previous studies [3,4], 37 MAPKKs were divided into four groups (groups A-D) (Fig. S2). However, no maize MAPKK genes belonged to groups $\mathrm{B}$ and $\mathrm{C}$ (Figs. S2 and S4), thereby implying that groups B and C MAPKK proteins might be lost in the maize genome after species differentiation. Although group D of MAPKKs contained genes from all four species, more than half (12 out of 20) came from maize (Figs. S2 and S4). This result indicates that the members of group D may have more important functions in maize than in other species, and gene expansion in this group could lead to a large maize MAPKK gene family.

All the 318 MAPKKKs from four different species formed three subfamilies, namely, MEKK, RAF, and ZIK (Fig. S3). Most of the groups or subfamilies contained members from all four species (Table 3, Fig. S3), implying that the genes within these classes were derived from a common ancestor. However, the number of SIMAPKKKs in the MEKK and ZIK subfamilies was larger than that in the same subfamilies in the other three species (Table 3), which indicates that gene expansion of tomato MAPKKKs mainly occurred in these two subfamilies.
Expression profile of SIMAPKK and SIMAPKKK genes in different tissues or organs

Expression analysis of SIMAPKKs revealed that most of these genes were constitutively expressed because their expression could be detected in most selected organs (Fig. 8). Relatively higher expression levels for SlMAPKK1 and SIMAPKK4 than those for other SIMAPKKs were found in tomato organs. The expression pattern of these two genes is different from that of their orthologs in Arabidopsis (MPSS database) and soybean [5]. The expression levels changed markedly among different organs/tissues. For example, SlMAPKK1 and SlMAPKK4 had the highest expression values in the root and stem, respectively, whereas SIMAPKK2 had a relatively high expression level in the flower.

No specific primers could be found to distinguish corresponding genes from each other because of the high similarity in nucleotide sequence between SIMAPKKK46 and SIMAPKKK4 and between SlMAPKKK50 and SlMAPKKK52. Thus, the expression patterns of all the tomato MAPKKK genes, except above four SIMAPKKK genes were analyzed. The expression of most SIMAPKKK genes was detected in all the selected organs (Figs. 9, 10, and 11). However, some genes were highly expressed in one or several specific organs. Twelve SIMAPKKKs from three subfamilies had higher expression levels in the root than that in other organs (Figs. 9, 10, and 11). Meanwhile, 13 SlMAPKKKs belonging to three subfamilies showed markedly higher expression levels in tomato stem than that in other organs (Figs. 10 and 11). Only three SIMAPKKKs (SIMAPKKK33, SlMAPKKK34, and SlMAPKKK35) were expressed with high abundance in fruits, while they were clustered at the end of chromosome 4 (Fig. 10).

\section{Expression patterns under various stress conditions}

MAPKK genes in plants are involved in response to various biotic and abiotic stresses. In Arabidopsis, MAPKK2 has an important function in the cold and salt signaling transduction pathway [13,14]. In maize, $Z m M A P K K 4$ is essential for salt and cold tolerance because the overexpression of $Z m M K K 4$ in Arabidopsis leads to insensitivity to salt and cold treatment [51]. Both AtMAPKK1 and AtMAPKK2 are associated with plant innate immunity [13-15]. In addition, AtMAPKK3 has a function in pathogen resistance $[17,18]$. In tomato, SIMAPKK2 acts with SlMPK2, thereby directly contributing to resistance to Xanthomonas campestris pv. vesicatoria [52]. In this study, the relative mRNA level of five SIMAPKKs changed significantly under heat, 

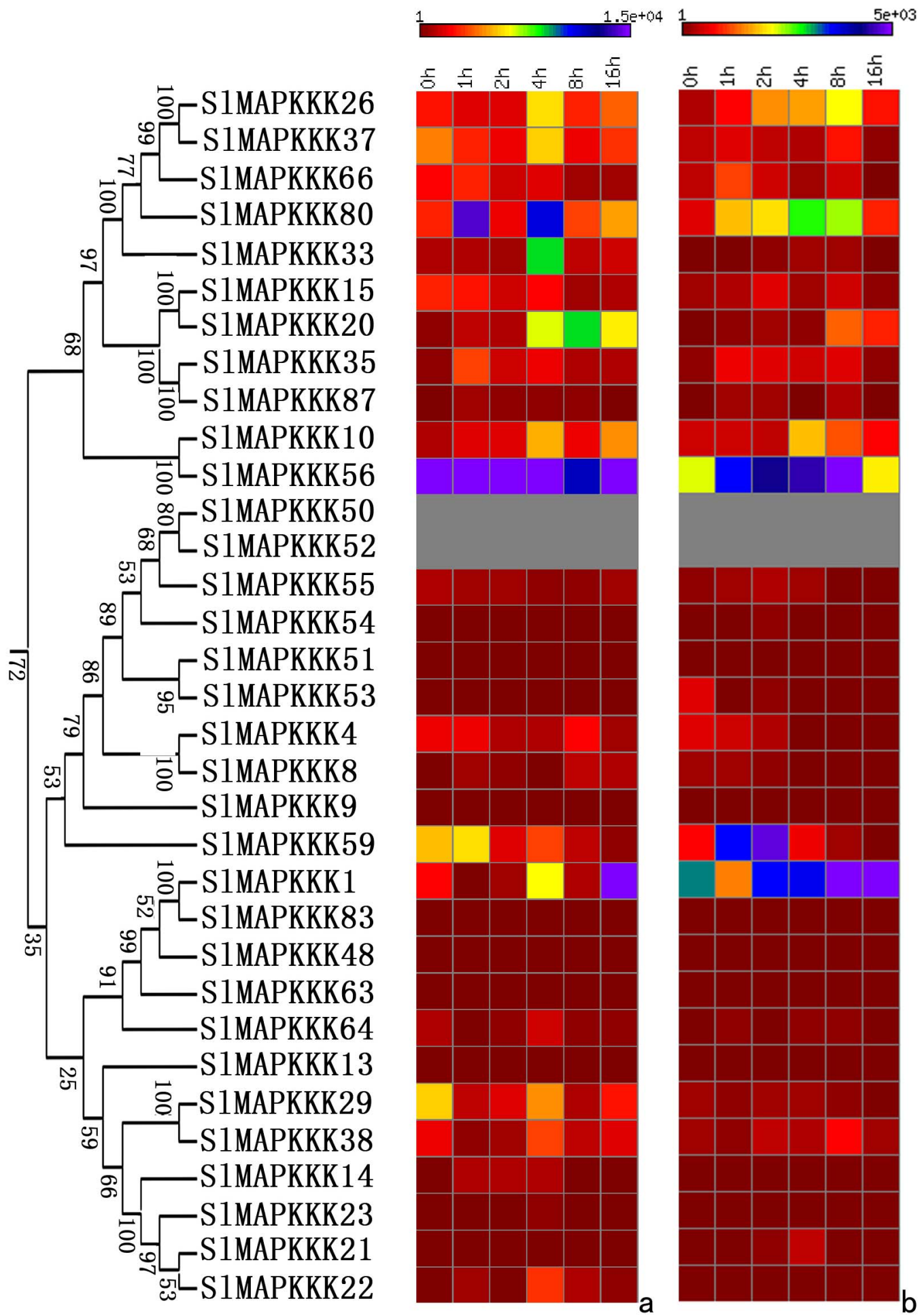

Figure 13. Expression profiles of MEKK subfamily genes with exogenous IAA (left) and SA (right) treatments. doi:10.1371/journal.pone.0103032.g013

cold, drought, and salt stresses (Fig. 8). All five SIMAPKK genes were upregulated by heat, cold, and drought treatment, whereas SlMAPKK2 and SIMAPKK5 were significantly upregulated by salt stress (Fig. 8). By contrast, the expression level of SlMAPKK4 was also dramatically upregulated (more than fourfold) after $P$. syringae treatment (Fig. 8), which indicates that SIMAPKK4 may also have an important function in the defense response to tomato pathogens.

The expression pattern of tomato MAPKKK genes under abiotic and biotic treatment was also analyzed in detail. Most of the SIMAPKKK genes were significantly upregulated by all four abiotic treatments (Figs. 9, 10, and 11), namely, heat, cold, drought, and salt. The relative mRNA levels of SlMAPKKK51, 

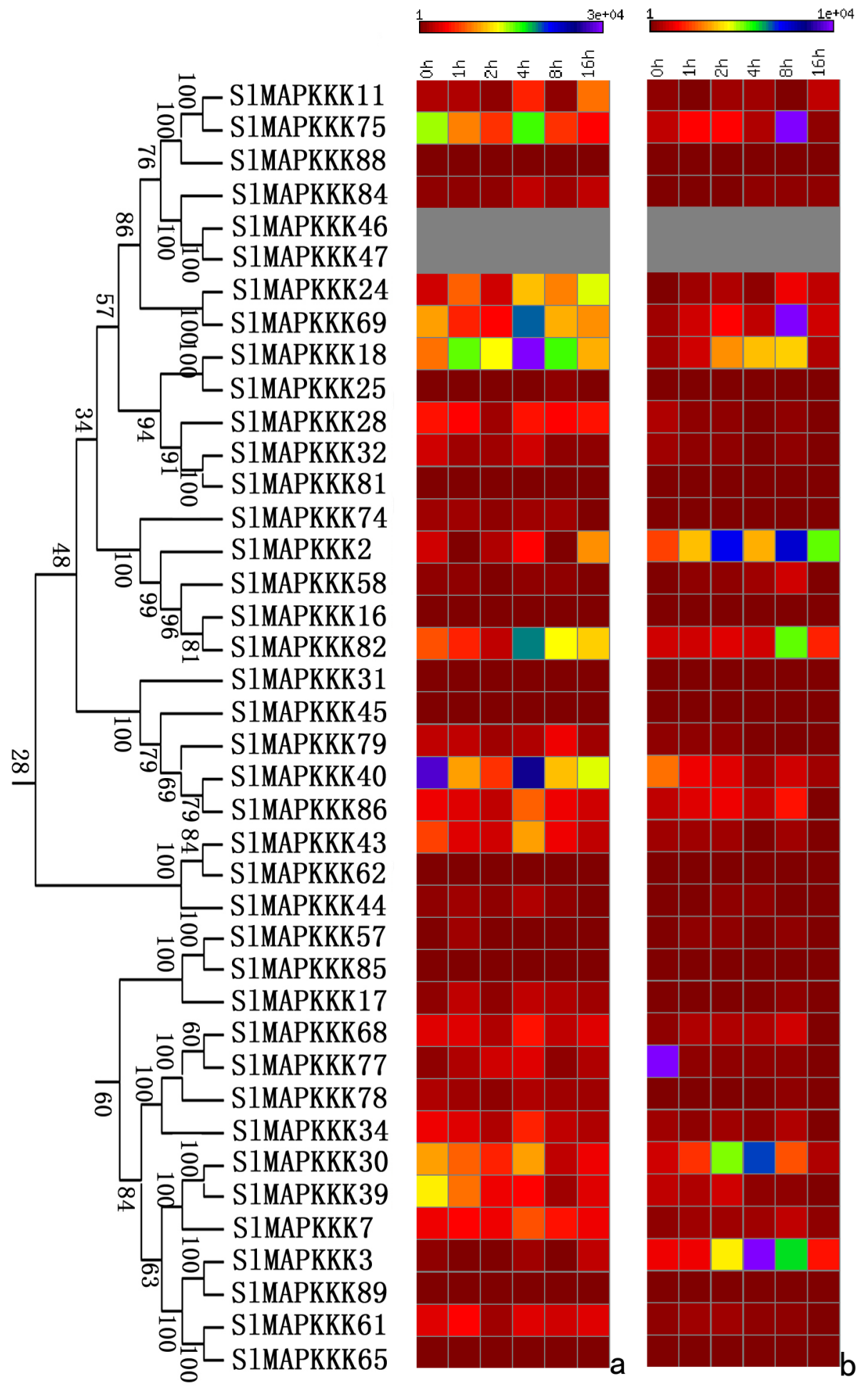

Figure 14. Expression profiles of RAF subfamily genes with exogenous IAA (left) and SA (right) treatments. doi:10.1371/journal.pone.0103032.g014

SlMAPKKK53, and SlMAPKKK55 were upregulated by more than 100-fold after heat or drought treatment (Fig. 9). Meanwhile, 13 MAPKKK genes showed a more than 10-fold change in expression levels under salt treatment (Figs. 9, 10, and 11). These data indicate that most SIMAPKKK genes were involved in the regulation of various abiotic stress signaling transduction path- ways. After $P$. syringae treatment, some SlMAPKKK genes were also remarkably upregulated. Especially for SlMAPKKK45, SlMAPKKK 48, and SlMAPKKK49, the relative mRNA levels were increased by more than 10-fold after treatment (Figs. 9, 10, and 11), indicating that these SlMAPKKK genes may have special functions in plant pathogen resistance. 

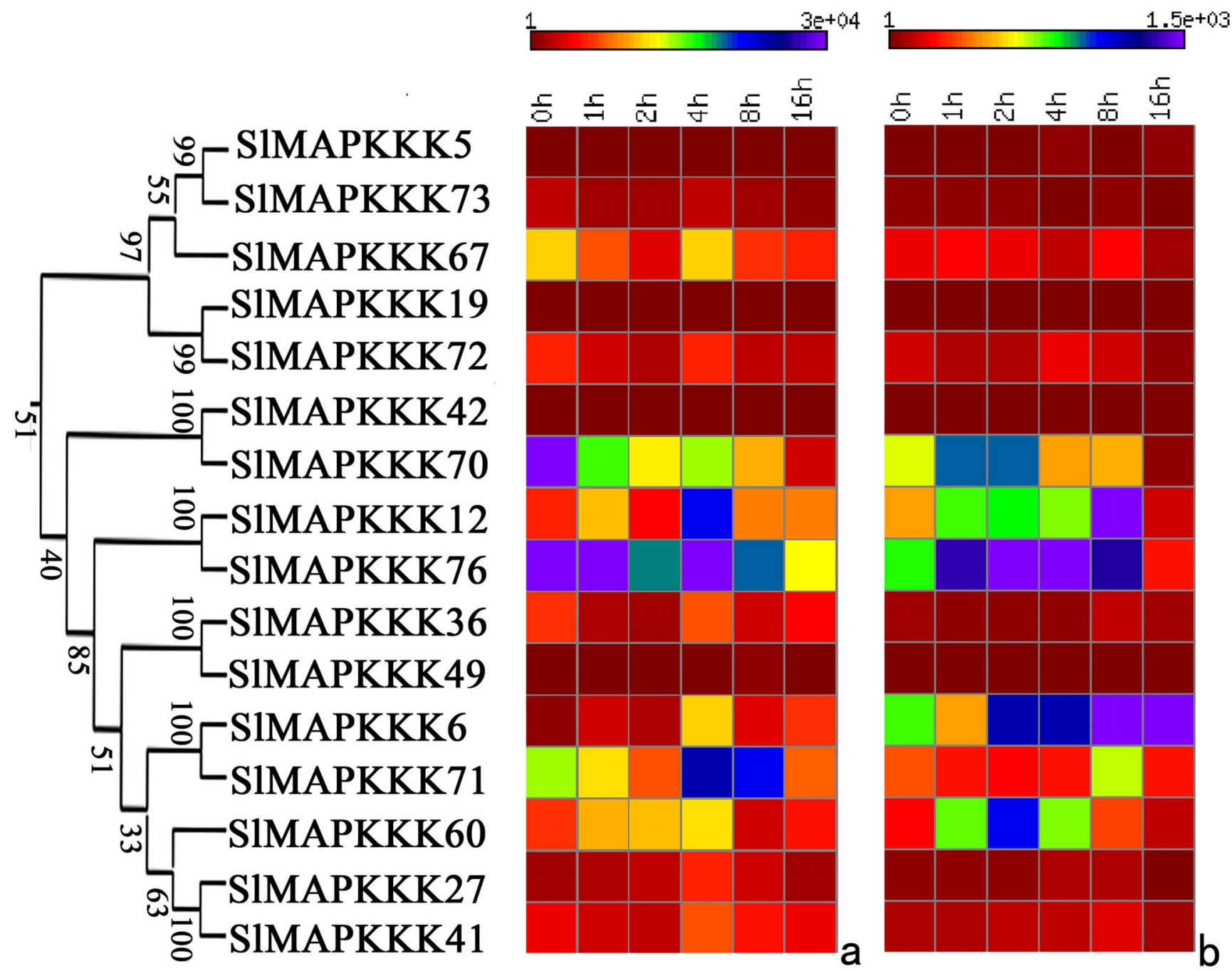

Figure 15. Expression profiles of ZIK subfamily genes with exogenous IAA (left) and SA (right) treatments. doi:10.1371/journal.pone.0103032.g015

The expression patterns of MAPKKK duplicated gene pairs were also investigated. Only three pairs (SIMAPKKK12 and SlMAPKKK76, SlMAPKKK6 and SlMAPKKK71, and SlMAPKKK4 and SlMAPKKK8) and one paralogous pair, including SlMAPKKK1, SlMAPKKK83, and SlMAPKKK84, shared similar expression patterns in nearly all stress conditions, whereas other paralogs were different. Although the duplicated SIMAPKKK genes had high similarity in amino acid sequences, they may have evolved a different expression pattern and function. Similar observations on the plant MAPKKK family have also been reported in maize [21] and soybean [5].

\section{Expression profiles under IAA and SA treatment}

MAPK cascades interact with or participate in the signal transduction of many plant hormones, such as auxin, ethylene, abscisic acid, SA, and jasmonic acid (JA) [32,53-55]. In this study, the expression patterns of tomato MAPKK and MAPKKK genes after exogenous IAA and SA treatment were analyzed in detail. All the SIMAPKKs except SlMAPKK3 and SlMAPKK5 were upregulated in response to IAA and SA treatment (Fig. 12). In Arabidopsis, MKK7 negatively regulates polar auxin transport and subsequently affects plant architecture [56]. In tobacco, the overexpression of SIPK enhances ozone-induced ethylene forma- tion and blocks ozone-induced SA accumulation [57]. JA can activate the MAPK cascade MKK3-MAPK6 and negatively regulate ATMYC2/JIN1 expression, thereby controlling Arabidopsis root growth [18]. All these results provide clear evidence of the involvement of the MAPKK pathway in response to hormone treatments.

The mRNA levels of most SIMAPKKKs varied considerably at different time periods after exogenous IAA and SA treatment (Figs. 13, 14, and 15). Almost half of the MEKK subfamily members were markedly upregulated by IAA and SA treatment, whereas others showed nearly no change with a relatively low expression level (Fig. 13). The RAF subfamily genes shared similar expression patterns with the MEKK subfamily (Fig. 14). However, all the ZIK subfamily members, except SlMAPKKK5, SlMAPK42, and SIMAPK49, had a remarkable response after IAA and SA treatment (Fig. 15). These data imply that most SIMAPKKK genes may be involved in plant hormone signaling during plant development and defense response. In rice, a MAPK gene, $B W M K 1$, responds to other plant hormones, such as JA, SA, and benzothiadiazole [58]. Using the Arabidopsis leaf protoplast transient expression system, Kovtun et al. proved that an oxidative stress MAPK cascade can negatively regulate early auxin response [59]. However, evidence of the involvement of MAPKKK in 
hormonal responses is limited. The patterns of interaction between the MAPK cascades and hormone signaling pathway need further investigation [60].

\section{Conclusion}

MAPK cascade family genes should be systematically analyzed to understand their functions in plant development and stress response. In this study, we present the genome-wide identification and analysis of the MAPKK and MAPKKK gene families in tomato. Five SlMAPKKs and 89 SlMAPKKKs were identified from the available tomato genome. Based on structural characteristics and a comparison of phylogenetic relationships among tomato, Arabidopsis, maize, and rice, all these MAPKK and MAPKKK genes were divided into four and three groups, respectively. Our results suggest that chromosomal segment duplications may be the main factors for the expansion of the MAPKKK gene family in tomato. Although nearly all the MAPKK and MAPKKK family genes were expressed in all the detected organs, some genes were highly expressed in one or several specific organs. The expression of most SIMAPKKs and SIMAPKKKs could be induced by both abiotic and biotic stress treatment. Most of the SIMAPKK and SIMAPKKK genes may interact with plant hormones, such as auxin and SA, during plant development and defense pathways. Our study could help improve the understanding of the complexity of the MAPKK cascade and guide future studies for functional analyses. The functions of organ-specific and stress-related genes in MAPK cascades and interaction with other signaling pathways in tomato are being characterized in our laboratory using overexpression and knockdown methods.

\section{Supporting Information}

Figure S1 Synteny analysis of SIMAPKKK genes in $\pm 100 \mathrm{~kb}$ region.

(DOCX)

\section{References}

1. Asai T, Tena G, Plotnikova J, Willmann MR, Chiu WL, et al. (2002) MAP kinase signaling cascade in Arabidopsis innate immunity. Nature 415: 977-983.

2. Lewis TS, Shapiro PS, Ahn NG (1998) Signal transduction through MAP kinase cascades. Adv Cancer Res 74: 49-139.

3. Ichimura K, Shinozaki K, Tena G, Sheen J, Henry Y, et al. (2002) Mitogenactivated protein kinase cascades in plants: a new nomenclature. Trends Plant Sci 7: 301-308.

4. Hamel LP, Nicole MC, Sritubtim S, Morency MJ, Ellis M, et al. (2006) Ancient signals: Comparative genomics of plant MAPK and MAPKK gene families. Trends Plant Sci 11: 192-198.

5. Neupane A, Nepal MP, Piya S, Subramanian S, Rohila JS, et al. (2013) Identification, nomenclature, and evolutionary relationships of mitogenactivated protein kinase (MAPK) genes in soybean. Evol Bioinform 9: 363-386.

6. Liu Y, Zhang D, Li W, Li D (2013) Genome-wide analysis of mitogen activated protein kinase gene family in maize. Plant Mol Biol Rep 31: 1446-1460.

7. Jonak C, Ökrész L, Bogre L, Hirt H (2002) Complexity, cross talk and integration of plant MAP kinase signalling. Curr Opin Plant Biol 5: 415-424.

8. Samuel MA, Ellis BE (2002) Double jeopardy: both over-expression and suppression of a redox-activated plant mitogen-activated protein kinase render tobacco plants ozone sensitive. Plant Cell 14: 2059-2069.

9. Cheong YH, Moon BC, Kim JK, Kim CY, Kim MC, et al. (2003) BWMK1, a rice mitogen-activated protein kinase, locates in the nucleus and mediates pathogenesis-related gene expression by activation of a transcription factor. Plant Physiol 132: 1961-1972.

10. Beck M, Komis G, Ziemann A, Menzel D, Šamaj J (2011) Mitogen-activated protein kinase 4 is involved in the regulation of mitotic and cytokinetic microtubule transitions in Arabidopsis thaliana. New Phytol 189: 1069-1083.

11. Kong FL, Wang J, Cheng L, Liu S, Wu J, et al. (2012) Genome-wide analysis of the mitogen-activated protein kinase gene family in Solanum lycopersicum. Gene 499: 108-120.

12. Hashimoto M, Komatsu K, Maejima K, Okano Y, Shiraishi T, et al. (2012) Identification of three MAPKKKs forming a linear signaling pathway leading to programmed cell death in Nicotiana benthamiana. BMC Plant Biology 12, 103.
Figure S2 The phylogenetic tree of MAPKK genes from Arabidopsis, tomato, rice, and maize.

(TIF)

Figure S3 The phylogenetic tree of MAPKKK genes from Arabidopsis, tomato, rice, and maize.

(TIF)

Figure S4 Phylogenetic analysis (Left), domain organization (middle) and exon-intron structures (right) of maize. ZmMAPKK genes.

(TIF)

Figure S5 The feature domain of ZmMAPKK proteins obtained with the ClustalX program.

(TIF)

Table S1 Primer sequences of SIMAPKK and SIMAPKKK genes for $q R T-P C R$ expression analysis.

(DOG)

Table S2 The cis-elements in promoter sequences of MAPKK genes in tomato.

(XLSX)

Table S3 The cis-elements in promoter sequences of MAPKKK genes in tomato.

(XLS)

Table S4 The characteristics of MAPKK family genes in maize.

(XLSX)

\section{Author Contributions}

Conceived and designed the experiments: J. Wu J. Wang GL. Performed the experiments: J. Wu J. Wang CTP. Analyzed the data: J. Wu J. Wang. Contributed reagents/materials/analysis tools: CTP YW XYG YJH JLG LFC. Wrote the paper: J. Wu J. Wang GL.

13. Oiu JL, Zhou L, Yun BW, Nielsen HB, Fiil BK, et al. (2008) Arabidopsis Mitogen-Activated Protein Kinase Kinases MKK1 and MKK2 have overlapping functions in defense signaling mediated by MEKK1, MPK4, and MKS1. Plant Physiol 148.1: 212-222.

14. Teige M, Scheikl E, Eulgem T, Doczi R, Ichimura K, et al. (2004) The MKK2 pathway mediates cold and salt stress signaling in Arabidopsis. Mol Cell 15: 14152.

15. Meszaros T, Helfer A, Hatzimasoura E, Magyar Z, Serazetdinova L, et al. (2006) The Arabidopsis MAP kinase kinase MKK1 participates in defense responses to the bacterial elicitor flagellin. Plant J 48: 485-98.

16. Melikant B, Giuliani C, Halbmayer-Watzina S, Limmongkon A, Heberle-Bors E, et al. (2004) The Arabidopsis thaliana MEK AtMKK6 activates the MAP kinase ATMPK13. FEBS Letters 576: 5-8.

17. Doczi R, Brader G, Pettko-Szandtner A, Rajh I, Djamei A, et al. (2007) The Arabidopsis mitogen-activated protein kinase kinase MKK3 is upstream of group $\mathrm{C}$ mitogen-activated protein kinases and participates in pathogen signaling. Plant Cell 19: 3266-79.

18. Takahashi F, Yoshida R, Ichimura K, Mizoguchi T, Seo S, et al. (2007) The mitogen-activated protein kinase cascade MKK3-MPK6 is an important part of the jasmonate signal transduction pathway in Arabidopsis. Plant Cell 19: 80518

19. Champion A, Picaud A, Henry Y (2009) Reassessing the MAP3K and MAP4K relationships. Trends Plant Sci 9: 123-129.

20. Rao KP, Richa T, Kumar K, Raghuram B, Sinha AK (2010) In silico analysis reveals 75 members of mitogen-activated protein kinase kinase kinase gene family in rice. DNA Res 17(3): 139-153.

21. Kong X, Lv W, Zhang D, Jiang S, Zhang S, et al (2013) Genome-Wide identification and analysis of expression profiles of maize mitogen-activated protein kinase kinase kinase. PLOS one 8: e57714.

22. Cristina MS, Petersen M, Mundy J (2010) Mitogen activated protein kinase signaling in plants. Annu Rev Plant Biol 61: 621-649.

23. Krysan PJ, Jester PJ, Gottwald JR, Sussman MR (2002) An Arabidopsis mitogenactivated protein kinase kinase kinase gene family encodes essential positive regulators of cytokinesis. Plant Cell 14: 1109-20. 
24. Lukowitz W, Roeder A, Parmenter D, Somerville C (2004) A MAPKK kinase gene regulates extra-embryonic cell fate in Arabidopsis. Cell 116: 109-19.

25. Ichimura K, Casais C, Peck SC, Shinozaki K, Shirasu K (2006) MEKK1 is required for MPK4 activation and regulates tissue-specific and temperature dependent cell death in Arabidopsis, J Biol Chem 281: 36969-76.

26. Nakagami H, Soukupova H, Schikora A, Zarsky V, Hirt H (2006) A mitogenactivated protein kinase kinase kinase mediates reactive oxygen species homeostasis in Arabidopsis. J Biol Chem 28: 38697-704.

27. Bergmann DC, Lukowitz W, Somerville CR (2004) Stomatal development and pattern controlled by a MAPKK kinase. Science 304: 1494-7.

28. Soyano T, Nishihama R, Morikiyo K, Ishikawa M, Machida Y (2003) NQK1/ NtMEK1 is a MAPKK that acts in the NPK1 MAPKKK-mediated MAPK cascade and is required for plant cytokinesis. Genes Dev 17: 1055-67.

29. Mitsumune MG, Brien MO, Bertrand C, Tebbji F, Nantel A, et al. (2006) Loss of ovule identity induced by overexpression of the fertilization-related kinase 2 (ScFRK2), a MAPKKK from Solanum chacoense. J Exp Bot 57: 4171-87.

30. del Pozo O, Pedley KF, Martin GB (2004) MAPKKK $\alpha$ is a positive regulator of cell death associated with both plant immunity and disease. EMBO J 23: 3072 82 .

31. Melech-Bonfil S, Sessa G (2010) Tomato MAPKKK? is a positive regulator of cell-death signaling networks associated with plant immunity. Plant J 64: 379391 .

32. Kieber JJ, Rothenberg M, Roman G, Feldmann KA, Ecker JR (1993) CTR1, a negative regulator of the ethylene response pathway in Arabidopsis, encodes a member of the raf family of protein kinases. Cell 72: 427-41.

33. Frye CA, Innes RW (1998) An Arabidopsis mutant with enhanced resistance to powdery mildew. Plant Ciell 10: 947-56.

34. Daisuke S, Daisuke M, Mariko O, Nariko S, Tomoyuki F, et al. (2011) MAP3K 84 , an Arabidopsis Raf-like MAP3K, regulates plant growth and shoot branching. Plant Biotechnol 28: 463-470.

35. Ning J, Zhang BC, Wang NL, Zhou EH, Li ZX (2011) Increased Leaf Angle1, a Raf-like MAPKKK that interacts with a nuclear protein family, regulates mechanical tissue formation in the lamina joint of rice. Plant Cell 23: 4334 4347 .

36. Ning J, Li X, Hicks LM, Xiong L (2010) A Raf-like MAPKKK gene DSM1 mediates drought resistance through reactive oxygen species scavenging in rice. Plant Physiol 152: 876-890.

37. Pedley KF, Martin GB (2004) Identification of MAPKs and their possible MAPK kinase activators involved in the Pto-mediated defense response of tomato. J Biol Chem 279: 49229-49235.

38. del Pozo O, Pedley KF, Martin GB (2004) MAPKKKa is a positive regulator of cell death associated with both plant immunity and disease. EMBO J. 23: 3072 3082.

39. Oh CS, Martin GB (2011) "Tomato 14-3-3 protein TFT7 interacts with a MAP kinase kinase to regulate immunity-associated programmed cell death mediated by diverse disease resistance proteins. J Biol Chem 286: 14129-14136.

40. Yu CS, Chih JL, Jenn KH (2004) Predicting subcellular localization of proteins for Gram-negative bacteria by support vector machines based on n-peptide compositions. Protein Sci 13: 1402-1406.

41. Thompson JD, Gibson TJ, Plewniak F, Jeanmougin F, Higgins DG (1997) The CLUSTAL_ windows interface: flexible strategies for multiple sequence alignment aided by quality analysis tools. Nucleic Acids Res 25: 4876-4882

42. Saitou N, Nei M (1987) The Neighbor-joining method: a new method for reconstructing phylogenetic trees. Mol Biol Evol 4: 406-425.
43. Liu Z, Lv Y, Zhang M, Liu Y, Kong L, et al. (2013) Identification, expression, and comparative genomic analysis of the IPT and CKX gene families in Chinese cabbage (Brassica rapa ssp. pekinensis). BMC Genomics 14: 594.

44. Cannon SB, Mitra A, Baumgarten A, Young ND, May G (2004) The roles of segmental and tandem gene duplication in the evolution of large gene families in Arabidopsis thaliana. BMC Plant Biology 4: 10.

45. Ramamoorthy R, Jiang SY, Kumar N, Venkatesh PN, Ramachandran S (2008) A comprehensive transcriptional profiling of the WRKY gene family in rice under various abiotic and phytohormone treatments. Plant Cell Physiol8 49: 865-879.

46. Wu J, Wang F, Cheng L, Kong F, Peng Z, et al. (2011) Identification, isolation and expression analysis of auxin response factor (ARF) genes in Solanum lycopersicum. Plant Cell Rep 30: 2059-2073.

47. Pavlidis P, Noble WS (2003) Matrix2png: a utility for visualizing matrix data. Bioinformatics 19: 295-296.

48. Saoto S, Latché A, Rousseau C, Regad F, Pech JC, et al. (2012) The tomato genome sequence provides insights into fleshy fruit evolution. Nature 485: 635641.

49. Kiegerl S, Cardinale F, Siligan C, Gross A, Baudouin E, et al. (2000) SIMKK, a mitogen-activated protein kinase (MAPK) kinase, is a specific activator of the salt stress-induced MAPK, SIMK. Plant Cell 12: 2247-2258.

50. Schauser L, Wieloch W, Stougaard J (2005) Evolution of NIN-like proteins in Arabidopsis, rice, and Lotus japonicus. J Mol Evol 60: 229-237.

51. Wu T, Kong XP, Zong XJ, Li DP, Li DQ (2011) Expression analysis of five maize MAP kinase genes in response to various abiotic stresses and signal molecules. Mol Biol Rep 38: 3967-3975.

52. Melech-Bonfil S, Sessa G (2011) The SIMKK2 and SIMPK2 genes play a role in tomato disease resistance to Xanthomonas campestris pv. vesicatoria. Plant Signal Behav 6: 154-156.

53. Mizoguchi T, Gotoh Y, Nishida E, Yamaguchi-Shinozaki K, Hayashida N, et al. (1994) Characterization of two cDNAs that encode MAP kinase homologues in Arabidopsis thaliana and analysis of the possible role of auxin in activating such kinase activities in cultured cells. Plant J 5: 111-122.

54. Xing Y, Jia W, Zhang J (2007) AtMEK1 mediates stress-induced gene expression of CAT1 catalase by triggering $\mathrm{H}_{2} \mathrm{O}_{2}$ production in Arabidopsis. J Exp Bot 58 (11): 2969-2981.

55. Mockaitis K, Howell SH (2000) Auxin induces mitogenic activated protein kinase (MAPK) activation in roots of Arabidopsis seedlings. Plant J 24: 785-796.

56. Dai Y, Wang H, Li B, Huang J, Liu X, et al, (2006) Increased Expression of MAP KINASE KINASE7 Causes Deficiency in Polar Auxin Transport and. Leads to Plant Architectural Abnormality in Arabidopsis. Plant Cell 18: 308320.

57. Samuel MA, Walia A, Mansfield SD, Ellis BE (2005) Overexpression of SIPK in tobacco enhances ozone-induced ethylene formation and blocks ozone-induced SA accumulation. J Exp Bot 56: 2195-2201.

58. Hong WF, He C, Wang L, Wang DJ, Joseph LM, et al. (2007) BWMK1 responds to multiple environmental stresses and plant hormones. J Integr Plant Biol 49: 843-851.

59. Kovtun Y, Chiu WL, Tena G, Sheen J (2000) Functional analysis of oxidative stress-activated mitogen-activated protein kinase cascade in plants. Proc Natl Acad Sci USA 97: 2940-5.

60. Mockaitis K, Howell SH (2000) Auxin induces mitogenic activated protein kinase (MAPK) activation in roots of Arabidopsis seedlings. Plant J 24: 785-796. 